\title{
OCCUPATIONAL CHOICE AND THE QUALITY OF ENTREPRENEURS
}

\author{
Eren Inci* \\ Boston College
}

March 2007

\begin{abstract}
This paper focuses on the quality of entrepreneurs when individuals, who differ in terms of entrepreneurial ability and wealth, choose between entrepreneurship and wage-earning. A loan is required to become an entrepreneur. Four wealth classes form endogenously. Banks' inability to identify the ability of individuals leads them to offer pooling contracts to the poor and the lower-middle classes. Regardless of ability, all poor class individuals become workers and all lower-middle class individuals become entrepreneurs. Banks are able to offer separating contracts to the upper-middle and the rich classes. High-ability individuals in these wealth classes become entrepreneurs and their low-ability counterparts become workers. Equilibrium contracts may entail cross-subsidies within or between occupations. In some economies, a small success tax on entrepreneurs used to subsidize workers can increase the average quality of entrepreneurs and welfare by changing the thresholds of the wealth classes. In some others a reverse policy is required. Since the aggregate level of investment is fixed, the reason for these policies is not under- or overinvestment by entrepreneurs, as it often is in previous literature.
\end{abstract}

Keywords: adverse selection; entrepreneurship; general equilibrium contract theory; moral hazard; occupational choice; success tax; wage subsidy

JEL Classification: D43; D82; H25; L26

${ }^{*}$ Tel.: 1-617-552-3670; fax: 1-617-552-2308. Address: Boston College, Department of Economics, 140 Commonwealth Avenue, Chestnut Hill MA 02467-3806 USA. E-mail address: inci@bc.edu. I am grateful to David de Meza, Avinash Dixit, Nobuhiro Kiyotaki, Tomas Sjostrom, Hi-Lin Tan, the dissertation workshop participants at Boston College (2005, 2005, 2006, 2006), session participants at the CEBR Conference on Entrepreneurship: Occupational Choice and Financing (2006), the Cambridge-MIT Institute Workshop on Regional Innovation (2006), the European Meeting of the Econometric Society (2006), seminar participants at the Center for European Economic Research (ZEW) (2006), the University of Aberdeen (2007), Bilkent University (2007), Sabanci University (2007), the Norwegian School of Economics and Business Administration (2007), Georgia Institute of Technology (2007), the University of Mannheim (2006, 2007), Boston University (2006), and especially James Anderson, Richard Arnott, Susanto Basu, and Andrew Newman for helpful comments. Some of the ideas presented here were developed while I was attending three NBER Entrepreneurship Group Meetings in 2005. This research is financially supported by the Paula and Daniel Greeley Award and the Boston College Dissertation Fellowship Award. The travel grants given by the NBER Entrepreneurship Group and the Cambridge-MIT Institute are also gratefully acknowledged. All errors are mine. 


\section{Introduction}

It is already well known that entrepreneurship has an enormous effect on the performance of an economy. In most countries, this fact is commonly reflected in policy in the form of subsidies aimed at increasing the number of entrepreneurs. Yet what guarantees that the individuals who become entrepreneurs as a result of these policies will be productive entrepreneurs rather than unproductive or destructive ones? As is well-documented by Baumol (1990) and Murphy, Shleifer, and Vishny (1991), the misallocation of talent is a rather robust phenomenon across time and space. Most cross-sectional data available - if not all - on entrepreneurs show that GDP per capita is quite unrelated to the number of entrepreneurs per capita. ${ }^{1}$ Moreover, Blanchflower (2000) shows that a higher number of entrepreneurs is not necessarily associated with higher growth rates in OECD countries, and Blanchflower (2004) indicates "more may not be better." Combining all of these results with the stigma of failure reported all over the world, it is obvious that entrepreneurship is a matter of quality more than a matter of quantity. It is this quality problem that this paper focuses on. It is easy to make individuals entrepreneurs but difficult to find the good ones. Markets often prevent some high-ability individuals (in terms of entrepreneurial abilities) from pursuing entrepreneurship while they encourage some low-ability individuals to become entrepreneurs. How can the government increase the average quality of entrepreneurs, and thus improve the performance of the economy? Could it be possible to do so even though the government does not know who are the high-ability and low-ability individuals?

I focus on a simple occupational choice problem in which there are two types of agents who differ in terms of unobservable entrepreneurial abilities, referred to as high-type and low-type agents. Agents also differ with respect to their wealth (which is liquid and observable by banks). They face a decision whether to become entrepreneurs or workers. There are two further links between entrepreneurship and wage-earning besides one being the outside option of the other. First, entrepreneurs hire workers. Second, the wealth endowments of the workers are lent to entrepreneurs in the financial markets. In the presence of such interlinkages in a general equilibrium setting, it is less clear ex ante whether creating disincentives in one occupation would create better outcomes economy-wide and in that occupation. Indeed, this paper shows that in some economies - but not in all - a tax on entrepreneurs used to subsidize workers can increase the average quality of entrepreneurs in the economy. That is, the common practice of subsidizing entrepreneurs might not work.

If agents decide to become entrepreneurs, they have to borrow from banks since their wealth alone is not enough to fully finance their firms. Every agent has the same probability of success in entrepreneurship, but high-type agents may increase this probability by working hard. When the net present value of the projects of low-type agents is negative but that of high-type agents who provide effort is positive, low-type agents would have no incentive to apply for loans in a perfect world. In an imperfect world, however, they may try to get loans because of the cross-subsidization

\footnotetext{
${ }^{1}$ For example, the data from Global Entrepreneurship Monitor (Acs, et al., 2005; GEM hereafter) shows that there are countries with similar levels of entrepreneurial activities yet with quite different GDP levels (such as Ireland, Iceland, Greece, Canada United States, Norway, and Switzerland). There are also relatively poor countries with various levels of entrepreneurial activities (such as South Africa, Argentina, Brazil, Jamaica, and Venezuela). Incorporating different definitions of entrepreneurship (i.e., nascent entrepreneurship, new, established, or total number of business owners) does not change the dispersed figure. Table 1 in Gollin (forthcoming), which is based on the Penn World Tables and the International Labor Organization Yearbook, and the self-employment data from OECD for any year also reflect similar dispersed scatter plots.
} 
in the loan market triggered by adverse selection. Equilibrium requires that entrepreneurs selffinance their firms with their own wealth as much as possible and borrow the rest from banks. All loanable funds come from those who become workers. Thus, the number of entrepreneurs is simply the aggregate wealth available in the economy divided by the fixed capital requirement to start a firm. This implies that the number of entrepreneurs in the economy is fixed, which allows me to explore the effects of policies on the quality of the entrepreneurs alone.

The paper first derives the contracts offered by banks and analyzes the decisions of the agents in a partial equilibrium when the factor prices are given. Different equilibrium contracts emerge in every wealth level as a result of the assumption that the wealth is observable by banks. The contractual structure endogenously forms four different wealth classes in the society: the poor, the lower-middle, the upper-middle, and the rich.

Banks have no choice but to offer pooling contracts to the poor and the lower-middle classes since it is always beneficial for low-type members of these wealth classes to misrepresent themselves as high-type agents. A pooling contract requires that high-type agents cross-subsidize low-type agents in the loan market. The fact that only pooling contracts can be offered in these wealth classes affects the occupational structure in different ways. In the poor class, it distorts the occupational decisions downward by isolating high-type agents from the loan market, and thus, from entrepreneurship. The reason is that high-type agents in this class are so poor that they cannot both provide effort in entrepreneurship and also cross-subsidize low-type agents in the loan market. Knowing this, banks set the interest rate high enough so that none of the agents in the poor class will prefer to apply for loans. Hence, all poor class agents, whether high- or low-type, become workers. However, in the lower-middle class, the pooling contracts distort occupational decisions upward by allowing the low-type agents to become entrepreneurs. On the one hand, high-type agents in this wealth class can provide effort in entrepreneurship even though they have to cross-subsidize low-type agents in the loan market; on the other hand, cross-subsidies make loans attractive to low-type agents. As a result, both high- and low-type agents prefer becoming entrepreneurs in the lower-middle class.

In the upper-middle wealth class, banks can offer separating contracts that limit prices the loans. Thus, low-type agents become workers and high-type agents become entrepreneurs in this wealth class. There is still cross-subsidization even though separating contracts are offered, but now it is in the form of information rents between the occupations. That is, the fact that the types cannot be observed causes transfers from high-type entrepreneurs to low-type workers. However, these information rents are efficient since they do not distort the occupational decisions, and hence do not affect who can use the capital. Finally, banks offer first-best efficient separating contracts to the rich class agents. Rich low-type agents need to borrow much less to start their firms, and thus, they do not benefit much from wrongfully revealing their types to be able to get loans. Hence, even a first-best efficient contract is incentive-compatible in this wealth class, and as a result, rich low-type agents become workers while their high-type counterparts become entrepreneurs.

After determining the equilibrium contracts and decisions of agents, I show that the equilibrium characterized in this partial equilibrium can exist in a general equilibrium, and then I present a policy exercise in that setting when the labor and the credit markets are interlinked. This analysis demonstrates how a small tax on entrepreneurs used to subsidize workers may increase the average quality of the pool of entrepreneurs in the economy by changing the boundaries of the wealth classes. The intuition goes as follows. Although the tax-subsidy policy affects all agents, its magnitude varies in different groups. In the economies on which I focus, the policy restructures 
the incentive schemes in the markets in such a way that agents who switch from entrepreneurship to wage-earning as a result of the policy are relatively wealthier than agents who do the opposite. This increases the loan supply to the banks, and thus, decreases the risk-free interest rate. The decrease in the risk-free interest rate - equal to the cost of loanable funds - also means a decrease in the lending interest rate.

Cross-subsidization in the loan market is the only reason why low-type agents may be attracted to entrepreneurship. Therefore, they prefer becoming entrepreneurs only if a sufficiently large portion of their projects is financed by banks. A decrease in the lending interest rate decreases the cross-subsidies per unit of loan borrowed by low-type agents. This mitigates the distortions of the adverse selection by discouraging some low-type agents from becoming entrepreneurs. Those who change their occupational decisions from entrepreneurship to wage-earning are low-type agents with greater wealth in the lower-middle class. Since there is a fixed number of entrepreneurs in the economy, the entrepreneurship positions emptied by them must be filled by some other agents. Who would they be? When the lending interest rate decreases, some of the poor hightype agents who used to be isolated from the loan market because they could not provide effort in entrepreneurship are now able to do so, and thus, banks can provide loans to them. However, when they become entrepreneurs, their low-type counterparts can also become entrepreneurs as a result of the pooling contracts offered in the lower-middle class. Thus, the overall effect of the policy is to swap some lower-middle class low-type entrepreneurs with an equal number of poor class high- and low-type workers. Given a fixed pool of entrepreneurs, the average quality of the entrepreneurs in the economy has to increase, and so does the welfare.

The model exhibits some empirical regularities, such as the fact that entrepreneurship is high in the countries where wages are higher, or the well-known fact that higher (lower) wages are associated with developed (developing) countries. It also shows at least one reason why policies for promoting entrepreneurship should be tailored to a country's specific context as indicated in the GEM. The GEM suggests a "one size does not fit all" policy. For example, low-income nations need to increase family income before focusing exclusively on entrepreneurs. I show that the market failures in the credit market distort the economy only in the poor and the lower-middle classes. Since relatively more people live in these wealth classes in poor countries, the problems in the entrepreneurial sectors hit the poor nations more than the rich ones. As individuals accumulate wealth and move up in the wealth distribution, adverse selection either turns into an efficient information rent (as in the upper-middle class) or completely disappears (as in the rich class). This helps shed light on why entrepreneurial sectors improve in the later phases of economic development.

The paper is organized as follows. Section 2 provides a brief comparison of this paper with the current literature on entrepreneurship. Section 3 presents the model. Section 4 focuses on the partial equilibrium in the credit market. Section 5 extends the analysis to a general equilibrium. Section 6 explores the effects of success taxes and wage subsidies. Section 7 concludes the paper. Appendix A contains derivations of some of the contracts and Appendix B contains some of the proofs.

\section{Literature Review}

The literature on the economic theory of entrepreneurship has grown rapidly in the recent years. Here, I shall confine myself to a selection of papers that are closely relevant to mine. The idea 
behind this paper is motivated by de Meza and Webb (2000) who show that sometimes the most effective policy is to subsidize the (exogenous) outside option to entrepreneurship.

A long strand of papers questions if the aggregate level of investment by entrepreneurs is too high or too low in the partial equilibrium. Perhaps the most famous of these are Stiglitz and Weiss (1981) and de Meza and Webb (1987). When the cost of loanable funds is exogenous, Stiglitz and Weiss (1981) (and its successors) argues that lending interest rates can be inefficiently high, and if so, aggregate investment will be inefficiently low. This calls for a subsidy to entrepreneurship. On the other hand, de Meza and Webb (1987) (and its successors) shows that under other plausible assumptions there can be excessive lending to entrepreneurs, and thus, overinvestment in the aggregate. This calls for a tax on entrepreneurship. However, when the cost of loanable funds is endogenous, insufficient or excessive lending is not an issue since the aggregate level of investment is fixed. Thus, the tax/subsidy policy in my paper increases welfare for a different reason than that of an overinvestment (or underinvestment) problem in the aggregate. Instead, it works by improving the quality composition of entrepreneurs in the economy.

Ghatak, Morelli, and Sjostrom (forthcoming) ${ }^{2}$ develops another occupational choice model in which the labor and credit markets are interlinked and provide another reason why a tax on entrepreneurs might be desirable. In its base model, a tax on entrepreneurs is always desirable and since the risk-free interest rate is exogenous, the main channel through which the policy works is the adjustment in the labor demand and its repercussions for the rest of the economy. I endogenize the risk-free interest rate by taking workers to be the source of loanable funds. The policy in my model changes the wealth class thresholds endogenously and it works through an adjustment to the loan supply to the banks, which in turn affects the risk-free interest rate in the economy. Moreover, a tax on entrepreneurs is not always desirable in my model; it depends on the economic environment of the economy, such as its wealth distribution. Below I argue why I believe that the risk-free interest rate can adjust as a result of changes in occupational structure. The credit market is also modeled differently in my paper. In the screening section of GMS, banks can make positive profits with separating contracts. However, in my setting there is no positive profit for banks in equilibrium, because banks can deviate to a cross-subsidizing separating contract via which the low-type agents are "paid" not to become entrepreneurs. GMS does not allow for this kind of a contract. In that sense, in GMS, there is a direct effect of wage increase: with a higher outside option it becomes easier to separate high-type agents from low-type agents. In contrast, in my paper, banks do not need government intervention since they themselves can raise the outside option on their own by offering cross-subsidizing contracts. ${ }^{3}$

One common assumption in the literature is that loans are infinitely supplied, possibly from international markets (see, for example, GMS, and de Meza and Webb (1987, 2000)). This means that the cost of funds to the banks, equal to the risk-free interest rate, is fixed. This partial analysis can be a good approximation when the entrepreneurial sector of the economy is relatively small and occupational choices do not have much effect on the factor prices (the risk-free interest rate and wages), which might happen in the short-run. My focus is the long-run, as it should be for a policy analysis. In my general equilibrium model, the occupational choices do affect the factor prices. The evidence in support of this argument is reported by Reynolds and White (1997): by the end of their working lives, about $2 / 5$ of the U.S. workforce have had at least one spell of self-employment, which is quite enough to affect the factor prices in the long-run. Even for

\footnotetext{
${ }^{2}$ GMS hereafter.

${ }^{3}$ I thank Tomas Sjostrom for pointing out this difference.
} 
small open economies, the occupational decisions of agents can affect factor prices in the long-run, owing to imperfect financial markets and limited lending to any specific country. Indeed, despite the globalization movements in recent decades, the Feldstein and Horioka Puzzle (1980) - which presents the empirical regularity that the long-run average of national savings is highly correlated to domestic investment - remains one of the six major puzzles in international macroeconomics (Obstfeld and Rogoff, 2000).

The paper is related to Parker (2003) which explores various tax policies regarding entrepreneurship (in particular differential tax treatment of occupations) in an imperfect credit market model in which ability applies both to entrepreneurship and wage-earning. The paper is also related to Gruner (2003), which finds that ex ante complete redistribution of endowments may lead to Pareto improvement by increasing the risk-free interest rate. However, in my setting, the small tax-subsidy policy is in the ex post sense and works by decreasing the risk-free interest rate. There is also a huge body of papers on occupational choice on which this paper builds on such as Banerjee and Newman (1993), Lloyd-Ellis and Bernhardt (2000), Ghatak, Morelli, and Sjostrom (2001), and Mookherjee and Ray (2002).

\section{The Model}

I consider a one-period closed economy with many principals (banks) and many agents (individuals). Agents decide whether to become entrepreneurs (denoted by $E$ ) or workers (denoted by $W)$.

\subsection{Economic environment}

There are (at least two) banks (indexed by $z$ ) and a unit mass of agents (indexed by $i$ ). Agents are composed of $h$ high types and $1-h$ low types. They are assumed to be risk neutral, and hence, maximize their expected income by choosing their occupations. The type of an agent affects his payoff from entrepreneurship, but all agents are identical in terms of their abilities in wage-earning. Low-type agents succeed in entrepreneurship with probability $p_{L}$. High-type agents, on the other hand, have two options. They may either provide effort or shirk. If they provide effort they can increase their success probability to $p_{H}$, but this comes with an effort cost of $e>0$. If they shirk their success probability is $p_{L}$ and, hence, is the same as the success probability of low-type agents. Providing effort is prohibitively costly for low-type agents. Hereafter, high-type agents who choose to provide effort are denoted by $H$, and low-type agents and high-type agents who choose to shirk are denoted by $L$.

Every agent is endowed with one indivisible labor unit and wealth $A$. Wealth completely depreciates in one period when it stays unused. It is assumed that entrepreneurial ability is not correlated with wealth. ${ }^{4}$ The population is described by a continuously differentiable distribution function $G(A)$, which gives the measure of the population with wealth less than $A$. The probability density function is given by $g(A)$ with support $[0, I]$, where $I$ is the setup cost of starting a firm which is

\footnotetext{
${ }^{4}$ The model can easily be extended to the case in which wealth and ability are correlated. Section 7 of Inci (2006) - the web version of this paper - briefly discusses this extension.
} 
assumed to be the same for every agent. Aggregate wealth, which is also the average wealth, $\bar{A}$, is given by

$$
\bar{A}=\int_{0}^{I} A d G(A)
$$

\subsection{The sequence of events}

Figure 1 summarizes the sequence of the events. Everything happens in one period. Since everyone's wealth is less than $I$ those who become entrepreneurs have to borrow from banks to start their firms. ${ }^{5}$ At the beginning of the period (time- $t^{-}$), agents choose their occupations. Then, financial contracts are signed, investments are made, and production takes place. At the end of the period (time- $t^{+}$), payoffs are realized, and successful entrepreneurs pay wages to workers. Finally, agents pay off their loans and banks pay the interest rate for deposits in addition to principals.

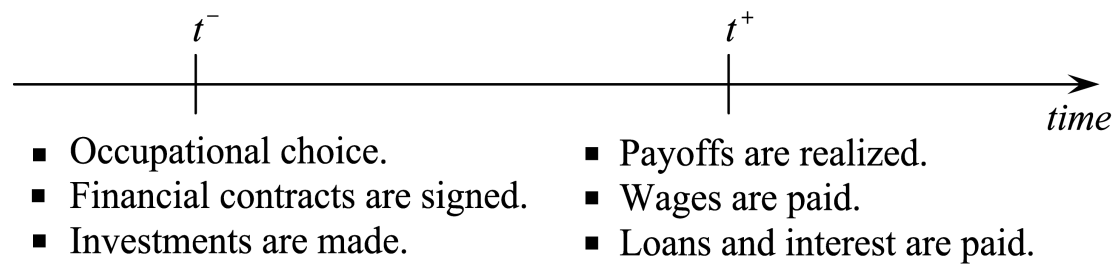

Figure 1: The Sequence of Events

\subsection{Information}

The types of agents are known only by them, but the distribution of types in every wealth level is public information. Wealth is perfectly observable by banks. Workers can observe neither the wealth nor the success probability of their employers. They cannot see the financial contracts between their employers and banks, either. However, they have rational expectations about the average success probability of the entrepreneurs in the economy. Output is verifiable, which implies that courts can enforce contracts.

\subsection{Banks}

Banks are risk-neutral and they compete in Bertrand fashion. They simultaneously form their beliefs and choose the contracts they will be offering, taking the risk-free interest rate, $R$, and the wage rate, $w$, as given. Since they observe the wealth levels, they may offer distinct contracts in every wealth level. Hence, given the factor prices, they offer contracts that are contingent on announced type and outcome (success or failure) in every wealth level. Let the repayment to the

\footnotetext{
${ }^{5}$ The analysis can be straightforwardly extended to the case where some agents' wealth exceeds $I$. None of the qualitative results of the paper depends on this assumption.
} 
bank by agent $i$ in the success state be $D_{i}^{S}(R, w, A)$ and $D_{i}^{F}(R, w, A)$ in the failure state. ${ }^{6}$ The most general form of the contract offered by bank $z$ is

$$
\boldsymbol{C}_{z}(A) \equiv\left[\begin{array}{l}
C_{H} \\
C_{L}
\end{array}\right]=\left[\begin{array}{ll}
D_{H}^{S}(R, w, A) & D_{H}^{F}(R, w, A) \\
D_{L}^{S}(R, w, A) & D_{L}^{F}(R, w, A)
\end{array}\right]
$$

where $C_{H}$ is the contract designed for high-type agents and $C_{L}$ is that for low-type and shirking high-type agents. ${ }^{7}$ I assume that there is limited liability. Therefore, the terms of contracts cannot leave agents with negative end-of-period payoffs:

$$
Y_{i}^{S} \geq 0 \quad \text { and } \quad Y_{i}^{F} \geq 0 \quad \forall i=H, L
$$

where $Y_{i}^{S}$ is the payoff of agent $i$ in the success state and $Y_{i}^{F}$ is the payoff of agent $i$ in the failure state.

\subsection{Entrepreneurs}

I define an entrepreneur as an individual who undertakes risky real investment in the form of starting a firm. Entrepreneurs are not only self-employed individuals but also employers. There is ownership, but no shareholdership.

Starting a firm requires at least $I$ units of capital, and labor is essential for production. Production is risky in the sense that it generates higher output only with probability $p_{i}$ and lower output with probability $1-p_{i}$ (lower output is normalized to zero). Therefore, the production technology is given by

$$
\left.f(k, l)=\left\{\begin{array}{cl}
f(l) & \text { with probability } p_{i} \\
0 & \text { with probability } 1-p_{i}
\end{array}\right\} \begin{array}{c}
\text { if } k \geq I \\
0 \\
\text { otherwise }
\end{array}\right\} \forall i=H, L
$$

where $k$ is capital, $l$ is labor and $f(l)$ is a strictly concave production function with diminishing marginal returns to labor (i.e., $\left.f(0)=0, f^{\prime}(l)>0, f^{\prime \prime}(l)<0\right)$. Production function is assumed to satisfy the Inada conditions (i.e., $\lim _{l \rightarrow 0} f^{\prime}(l)=\infty$ and $\lim _{l \rightarrow \infty} f^{\prime}(l)=0$ ).

With this technology, capital is still a decision variable. However, the decision is an all-or-none decision in the sense that agents decide whether to invest or not to invest. The model can be extended to allow agents to choose the number of projects they would like to manage in a similar fashion to Banerjee and Newman (1993). Then, I can be interpreted as the unit project size. Doing so would obviously produce more results, but it would not alter the intuitions in the present paper.

Since $A$ is not sufficient to fully cover the setup cost of a firm, entrepreneurs have to borrow a loan of $I-A$ from the bank. ${ }^{8}$ Then, the expected payoff of an entrepreneur, $\Upsilon_{i}^{E}(R, w, A)$, is given by

$$
\Upsilon_{i}^{E}(R, w, A):=p_{i}\left(f(l)-w l-D_{i}^{S}(R, w, A)\right)-\left(1-p_{i}\right) D_{i}^{F}(R, w, A)-m_{i} \quad \forall i=H, L \quad,
$$

${ }^{6}$ I do not put nonnegativity restrictions on repayments to banks. Later, I show that banks may offer contracts with $D_{L}^{S}(R, w, A)<0$ and $D_{L}^{F}(R, w, A)<0$ in some wealth levels. That is, they can give money to low-type agents to prevent them from applying loans.

${ }^{7}$ I shall drop subscript $z$ whenever it does not cause any confusion.

${ }^{8}$ Later, it is shown that there has to be maximum self-finance in equilibrium. 
where $m_{i}$ is defined by

$$
m_{i}=\left\{\begin{array}{ll}
e & \text { if } i=H \\
0 & \text { if } i=L
\end{array} .\right.
$$

An entrepreneur is going to be successful with probability $p_{i}$ and produce $f(l)$. He pays $w l$ to the workers and gives $D_{i}^{S}(R, w, A)$ to the bank. Thus, the expected net return in the success state is $p_{i}\left(f(l)-w l-D_{i}^{S}(R, w, A)\right)$. When he is unsuccessful he produces something less than $f(l)$ (which is normalized to zero), pays something less than $w l$ to the workers (which is normalized to zero), and gives $D_{i}^{F}$ to the bank. However, limited liability prevents $D_{i}^{F}$ from being higher than what the entrepreneur has. Since the output in case of failure is normalized to zero, $D_{i}^{F}$ is going to be zero as well, but for the sake of generality of the analysis, I start off without imposing the limited liability. ${ }^{9}$ For brevity, from now on, I shall denote net output in the success state with $\pi(w)$ :

$$
\pi(w):=\max _{\{l\}}[f(l)-w l]
$$

\subsection{Workers}

An agent who chooses to become a worker is employed at an entrepreneur's firm. Given the information structure in section 3.3, there has to be a random matching between entrepreneurs and workers. The common wage rate is $w$, and is paid only if the entrepreneur is successful. Let the weighted average of the success probabilities of entrepreneurs in the economy be $p^{e}$. Then, a worker's expected wage income is given by $p^{e} w$. Workers can also deposit their wealth into a bank and receive a risk-free (gross) interest rate of $R$. Hence, the expected payoff of an agent who becomes a worker, $\Upsilon_{i}^{W}(R, w, A)$, is given by

$$
\Upsilon_{i}^{W}(R, w, A):=p^{e} w+R A \quad \forall i=H, L
$$

Some of the risk of the firm is borne by the workers on this specification. ${ }^{10}$ This is similar to an efficiency wage scheme. Firms pay $w$ in a success state and a lower wage in a failure state where the lower wage is normalized to zero. This specification is consistent with the empirical findings that the returns to entrepreneurship vary more than returns to wage-earning. ${ }^{11}$

As indicated before, this paper concentrates on the occupational choice problem with the focus being on the entrepreneurs. As a natural simplification, I assume that all agents are equally able as workers. In the real world, however, agents differ in their abilities as workers as well. In such a world, an efficient allocation entails that those with a comparative advantage in entrepreneurship will become entrepreneurs. My assumption that all agents are equally able as workers eliminates the distinction between comparative and absolute advantage. ${ }^{12}$

\footnotetext{
${ }^{9}$ In a failure state, entrepreneurs pay neither the loans nor the wages in equilibrium. Thus, I do not need to make a statement about the seniority of the loan and wage payments.

${ }^{10}$ In this sense, the model diverts from the risk-based "Knightian" theory of entrepreneurship in which entrepreneurs bear all the risk of production. Newman (2006) shows that risk-based explanations for entrepreneurship are inadequate.

${ }^{11}$ In an alternative setting, payoff of a worker can be interpreted as the expected return to market portfolio in which one part is the riskless return on, say, government bonds and the other part is the risky return to a portfolio of stocks, and the payoff of an entrepreneur is a share of a firm.

${ }^{12}$ Parker (2003) works on a model in which ability applies to both occupations. Agents might have various entrepreneurial skills as well. This problem has been studied by Lazear (2005) which states that entrepreneurs
} 


\section{Partial Equilibrium}

This section focuses on the decisions of agents and banks when $w$ and $R$ are given. In Section 5 , I shall endogenize them. All of the contracts derived separately in the following sections are shown at once in Figure 6.

\subsection{Equilibrium definition}

An equilibrium is a set of contract offers by banks which are consistent with each other. Each bank offers agents a set of contracts that maximizes their profits. Agents choose the best contract for them among all alternatives. ${ }^{13}$ I impose a Wilson equilibrium concept (Wilson, 1977). ${ }^{14}$ In a Wilson equilibrium there is nonmyopic rationality in the sense that, during decision making, banks take into account the effects of their actions on the actions of the other banks. That is, a bank would not offer a deviation contract that would incur losses once the unprofitable contracts offered by all the other banks have been withdrawn. This rules out potential nonexistence issues analyzed in Rothschild and Stiglitz (1976). Formally, an equilibrium in the credit market is defined as follows.

Definition 1 (Equilibrium Concept) Assume that banks are nonmyopic Bertrand-Wilson players following pure strategies. Given $w$ and $R$, a credit market equilibrium is a set of contract offers by banks such that all sets of contracts earn nonnegative profits in every wealth level. There is no new set of contracts that could earn higher profits even after the elimination of all unprofitable sets of contracts.

An equilibrium must be individually rational for every agent. Individual rationality asserts that agents choose an occupation only if it is better than staying inactive. With the assumption of complete depreciation, this means

$$
\begin{aligned}
\Upsilon_{i}^{o}(A) & \geq 0 \quad \forall i=H, L \wedge \forall o=E, W \\
R & \geq 0 .
\end{aligned}
$$

An equilibrium has to be incentive compatible for every agent. Incentive compatibility assures that none of the agents has incentive to misrepresent his type:

$$
\begin{aligned}
\max \left\{\Upsilon_{H}^{E}(A), \Upsilon_{L}^{E}(A)\right\} & \geq \max \left\{p_{H} Y_{L}^{S}-e+\left(1-p_{H}\right) Y_{L}^{F}, \Upsilon_{L}^{E}(A)\right\} \\
\Upsilon_{L}^{E}(A) & \geq p_{L} Y_{H}^{S}+\left(1-p_{L}\right) Y_{H}^{F}
\end{aligned}
$$

must be jacks-of-all-trades who need not excel in any one skill, but are competent in many.

${ }^{13}$ Assuming free entry or fixed number of banks do not make any difference.

${ }^{14} \mathrm{~A}$ Wilson equilibrium can be obtained by changing the extensive form of a Nash game by allowing two rounds of play for banks, as is done in Hellwig (1987). First, banks announce the set of contracts they would like to offer. Then, they may withdraw as many contracts as they wish. Finally, agents choose the set of contracts they would like to accept. In that sense the two conjectures differ from each other in their extensive forms. Otherwise, the solution concept is still subgame perfection. The equilibrium concept defined in Definition 1 is a short-cut to this extensive form. In that sense, every Nash equilibrium is also a Wilson equilibrium, but there can be a Wilson equilibrium in cases in which there is no Nash equilibrium. 
The first one says that none of the high-type agents would be attracted by the contracts designed for low-type agents regardless of whether they provide effort or not. The second one says the same for low-type agents.

In an equilibrium, proper participation constraints must hold for every agent. Participation constraints guarantee that agents choose the occupation that makes them strictly better off:

$$
\begin{aligned}
& \Upsilon_{i}^{W}(A)>\Upsilon_{i}^{E}(A) \forall i, j=H, L \Longleftrightarrow W \succ_{i} E \quad \forall i=H, L \\
& \Upsilon_{i}^{W}(A)<\Upsilon_{i}^{E}(A) \forall i, j=H, L \Longleftrightarrow E \succ_{i} W \quad \forall i=H, L
\end{aligned}
$$

where $W \succ_{i} E$ means that agent $i$ strictly prefers wage-earning to entrepreneurship (similarly for $\left.E \succ_{i} W\right)$. It should also be specified what agents do when they are indifferent between the two occupations. The next assumption asserts that they choose wage-earning in such situations.

Assumption 1 (Occupational Indifference) $\Upsilon_{i}^{W}(A)=\Upsilon_{i}^{E}(A) \forall i, j=H, L \Longrightarrow W \succ_{i} E \forall i=$ $H, L$.

I also need to specify what agents do when they are equally attracted to different contracts. As stated in the next assumption, if agents have more than one best alternative, they choose one of them with equal probabilities.

Assumption 2 (Contractual Indifference) $\forall i=H, L \wedge \forall o=E, W \wedge \forall z, l=\{1, \ldots, n\}$ $\left\{\Upsilon_{i}^{o}(R, w, A) \mid C_{i z}(A)\right\}=\left\{\Upsilon_{i}^{o}(R, w, A) \mid C_{i l}(A)\right\} \Longrightarrow \operatorname{Pr}\left\{C_{i z}(A) \succ_{i} C_{i l}(A)\right\}=1 / n$.

Assumption 1 is an assumption about the preferences of the agents over occupations when they are indifferent between them. However, Assumption 2 is an assumption about the preferences of the agents over the set of contracts when they are indifferent between them. It states that they do not mind from whom they take the contract.

\subsection{The banks' problem}

I can now derive the set of contracts offered by banks. I start off by deriving the zero profit conditions for banks and the iso-profit lines for agents. The zero profit condition with only hightype agents who provide effort is

$$
p_{H}\left(\pi(w)-Y_{H}^{S}\right)-\left(1-p_{H}\right) Y_{H}^{F}=R(I-A)
$$

and the same with low-type or shirking high-type agents is

$$
p_{L}\left(\pi(w)-Y_{L}^{S}\right)-\left(1-p_{L}\right) Y_{L}^{F}=R(I-A) .
$$

The corresponding iso-profit lines are given by

$$
\begin{aligned}
p_{H} Y_{H}^{S}+\left(1-p_{H}\right) Y_{H}^{F} & =\bar{Y}_{H}^{E} \\
p_{L} Y_{L}^{S}+\left(1-p_{L}\right) Y_{L}^{F} & =\bar{Y}_{L}^{E},
\end{aligned}
$$


where $\bar{Y}_{H}^{E}$ and $\bar{Y}_{L}^{E}$ are levels of $Y_{H}^{E}$ and $Y_{L}^{E}$, respectively. Note that both iso-profit lines are parallel to the corresponding zero profit conditions for banks. Finally, the zero profit condition with both types is

$$
\bar{p} D^{S}+(1-\bar{p}) D^{F}=R(I-A)
$$

where $D^{S}$ is the repayment in the success state and $D^{S}$ is the repayment in the failure state of a random loan applicant with wealth level $A$, and $\bar{p}$ is the Bayesian success probability of him:

$$
\bar{p}=h p_{H}+(1-h) p_{L}
$$

Four different equilibria may arise depending on the wealth of a given agent. Figure 2 illustrates the threshold levels that separate these different equilibria in the $Y^{F}-Y^{S}$ space with some abuse of geometry. ${ }^{15}$ Limited liability requires that a contract lie in the first quadrant. $Z P_{H}, Z P_{L}$, and $Z P_{H L}$ are the graphs of zero profit conditions (12), (13), and (15), respectively, for a particular value of $A$. An agent's payoff in case he becomes a worker is given by (8). Call this payoff the outside option (to entrepreneurship).

There are low-type agents with a particular wealth level whose iso-profit lines passing through their outside option also pass through the point where $Z P_{H L}$ intersects the $Y^{S}$-axis. $L_{1} L_{1}^{\prime}$ is an iso-profit line for such agents. Denote their wealth level with $A_{L}$. There are also agents with a particular wealth level whose iso-profit lines passing through their outside option also pass through the intersection of $Z P_{H}$ and the $Y^{S}$-axis. $L_{2} L_{2}^{\prime}$ is an iso-profit line for such agents and I denote the wealth level that represents them with $\tilde{A}$. I derive the expressions for $A_{L}$ and $\tilde{A}$ when I analyze the decisions of agents.

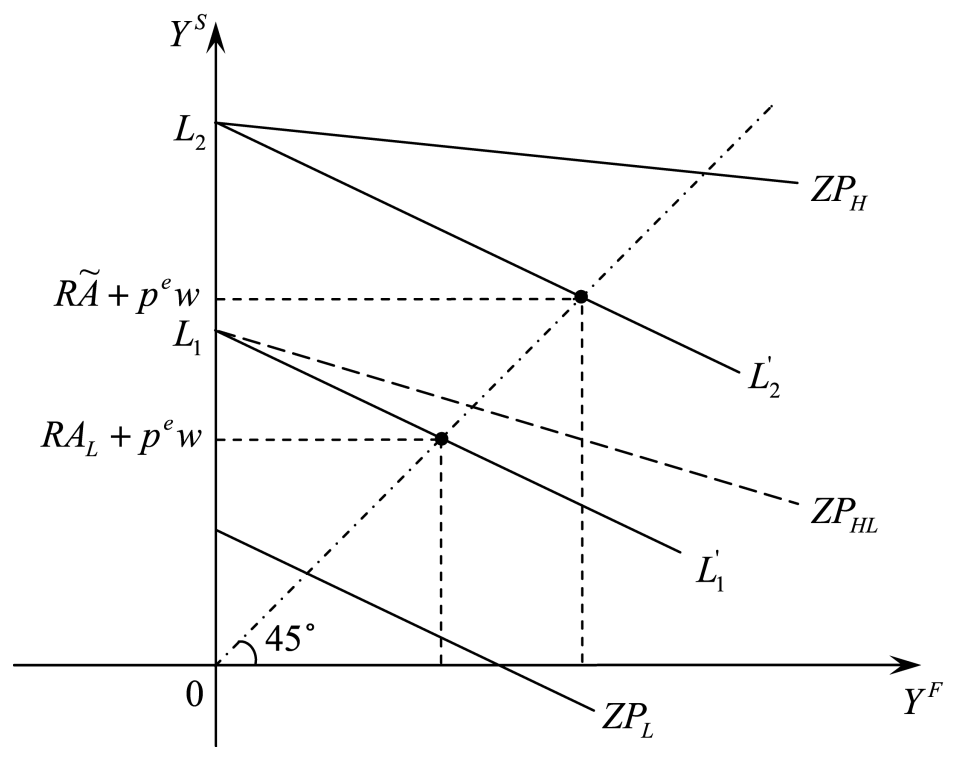

Figure 2: Contract Offers

It can be shown that for wealth levels between $\left[0, A_{L}\right]$, banks offer cross-subsidizing pooling contracts; for wealth levels between $\left[A_{L}, \tilde{A}\right]$, they offer cross-subsidizing separating contracts; and for wealth levels between $[\tilde{A}, I]$, they offer first-best efficient separating contracts which are accepted only by high-type agents who provide effort. All of these contracts assume that high-type

\footnotetext{
${ }^{15}$ The lines drawn are functions of $A$, and hence, their positions are different for different values of $A$. For expositional convenience, I show all lines at once in one graph.
} 
agents provide effort. There is no adverse selection problem in the wealth classes in which they do not provide effort, since whenever they do not provide effort they are no different from low-type agents in terms of their success probability. So, banks offer a pooling contract in these successprobability-wise homogenous wealth levels. Figure 2 does not show this possibility but Section 4.4 analyzes the effort decision of agents. ${ }^{16}$ The following proposition formally proves these findings.

Proposition 1 (Contracts) When high-type agents provide effort in entrepreneurship, banks offer the cross-subsidizing pooling contract $\boldsymbol{C}^{*}(A)$ to agents with wealth levels between $\left[0, A_{L}\right]$, cross-subsidizing separating contract $\boldsymbol{C}^{* *}(A)$ to agents with wealth levels between $\left[A_{L}, \tilde{A}\right]$, and the first-best efficient separating contract $\boldsymbol{C}^{* * *}(A)$ to agents with wealth levels between $[\tilde{A}, I]$. When high-type agents do not provide effort, banks offer the pooling contract $\boldsymbol{C}^{* * * *}(A)$.

Proof. See Section 4.3 for the derivation of the cross-subsidizing separating contracts. Appendix A contains the derivations of the rest of the contracts. $\boldsymbol{C}^{*}(A), \boldsymbol{C}^{* *}(A), \boldsymbol{C}^{* * *}(A)$, and $\boldsymbol{C}^{* * * *}(A)$ are defined in the proofs.

The proof of Proposition 1 highlights another important finding. When the strategy space of banks is large enough they can always find a set of deviation contracts such that positive profits are competed away. Positive profits arise only when the strategy space is restricted. For example, restricting the strategy space to loan contracts in which banks cannot give out money to the agents at the end of the period would result in positive profits. Given that agents produce nothing in the failure state and banks cannot give out money, the rents given to the low-type agents, and some portion of the end-of-period payoff of effort-providing high-type agents, are emitted by banks in the form of positive profits. Other than the cases in which there are such restrictions on the strategy space, there are always zero profits in this and similar games.

Lemma 1 (Banking Profits) When banks' strategy space is large enough, they make zero profits from every set of contract they offer.

Proof. See Section 4.3 and Appendix A.

In GMS banks can make positive profits with separating contracts whereas in my setting these profits can be competed away since banks can pay "higher interest rates" for the deposits of low-type agents just to keep them out of the loan market by offering cross-subsidizing separating contracts. Below I focus on the derivation of this contract and show how positive profits may arise when the strategy space is restricted.

\subsection{Cross-subsidizing separating contracts}

Banks offer cross-subsidizing separating contracts to the agents with wealth levels between $\left[A_{L}, \tilde{A}\right]$. They cannot offer pooling contracts because the outside option to entrepreneurship yields strictly higher payoffs than any pooling contract that makes zero profits with both types. This is shown in Figure 3. The iso-profit line that passes through the outside option of low-type agents is given by $L_{1} L_{1}^{\prime}$, and that of effort-providing high-type agents is given by $H_{1} H_{1}^{\prime}$. Any contract has to be on or

\footnotetext{
${ }^{16}$ Note that, in any given wealth level, either all or none of the high-type agents provide effort in entrepreneurship.
} 
over the upper envelope of these two iso-profit lines. Since $Z P_{H L}$ is below this envelope anywhere in the first quadrant, banks cannot design any pooling contract that can make nonnegative profits with both types.

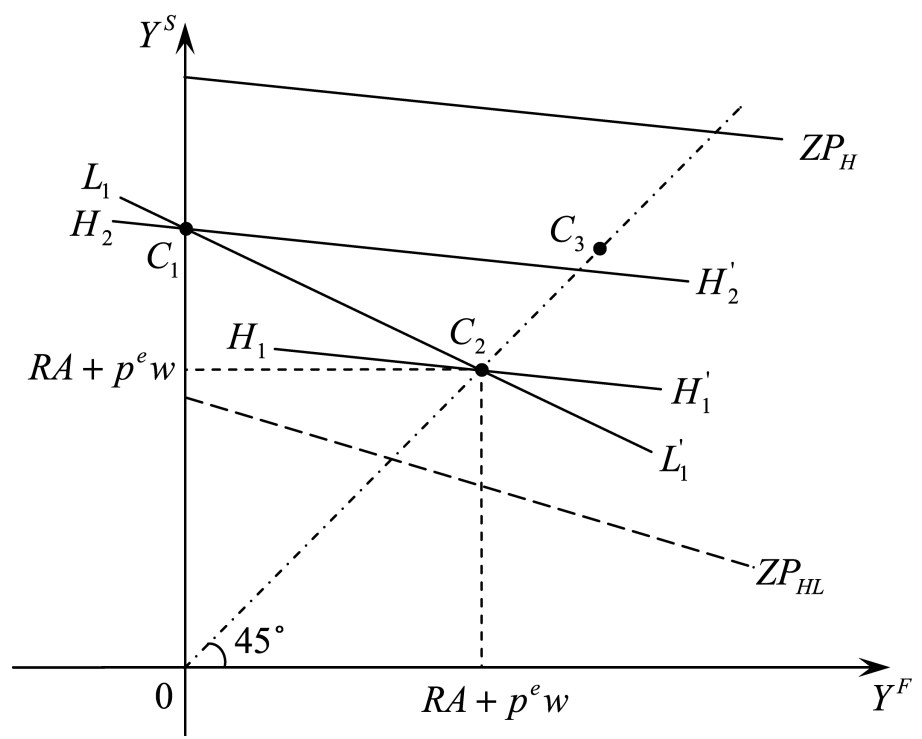

Figure 3: Positive Profits with a Restricted Strategy Space

The next point of concern is whether banks can design separating contracts. Start with the separating contract $\left(C_{1}, C_{2}\right)$. Banks offer the standard loan contract $C_{1}$ to high-type agents who provide effort. It is immediate to see that high-type agents strictly prefer $C_{1}$ over $C_{2}$. Banks offer $C_{2}$ to low-type agents, which differs from a standard loan contract. According to this contract, low-type agents deposit their wealth with the bank and get a job. At the end of the period, they receive a gross interest income of $R A$ from the bank and an expected wage of $p^{e} w$ from their employer. Contract $\left(C_{1}, C_{2}\right)$ makes low-type agents indifferent between the two occupations. By assumption 1, they choose wage-earning, and therefore, stay out of entrepreneurship.

As far as the "loan contracts," which determine the nonnegative repayments to the banks at the end of the period, are concerned, $\left(C_{1}, C_{2}\right)$ is an equilibrium in which banks make positive profits. However, the strategy space of banks is not limited to loan contracts only. A bank can undercut this contract by offering some amount of money to low-type agents in both states of the world in addition to the usual interest income it offers to the deposits. This would be a plausible deviation as long as the incentive compatibility condition for effort-providing high-type agents is not violated (e.g., the deviation contract must be above $H_{2} H_{2}^{\prime}$ ). Such a contract is shown with $\left(C_{1}, C_{3}\right)$ in Figure 3 . There is always such a deviation contract in $\left[A_{L}, \tilde{A}\right]$ since $Z P_{H}$ is always above, and any contract on $Z P_{H}$ makes zero profits with effort-providing high-type agents.

Undercutting goes on until banks make zero profits with these contracts. Then, what would be the equilibrium? Start with $\left(C_{1}, C_{2}\right)$ in Figure 4, and move the iso-profit line of low-type agents parallel to $L_{1} L_{1}^{\prime}$. There has to be a separating contract $\left(C_{H}^{* *}, C_{L}^{* *}\right)$ in between $L_{1} L_{1}^{\prime}$ and $Z P_{H}$ such that effort-providing high-type agents strictly prefer $C_{H}^{* *}$, and low-type agents weakly prefer $C_{L}^{* *}$. In such a situation, by Assumption 2, agents choose one of the contracts offered in the market with equal probabilities. Banks make profits on $C_{H}^{* *}$ and incur losses on $C_{L}^{* *}$. In the end, the equilibrium contract is the separating contract $\left(C_{H}^{* *}, C_{L}^{* *}\right)$ that makes zero profits, but it still requires cross-subsidization between the types. 


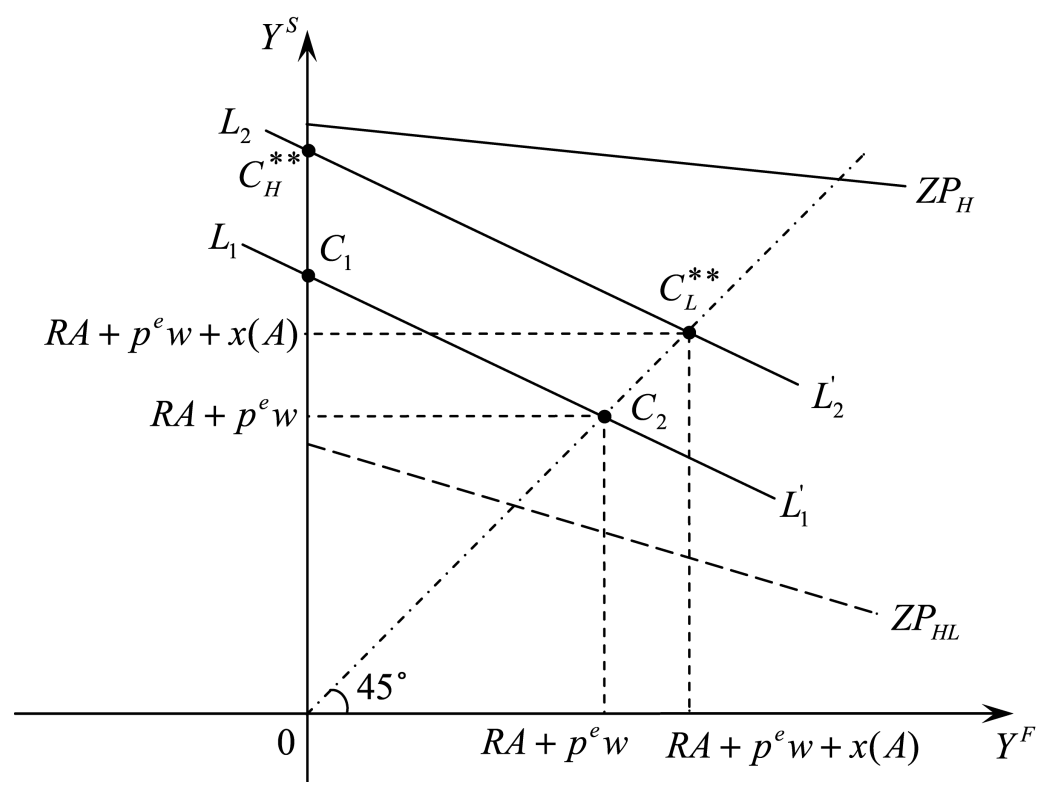

Figure 4: Cross-subsidizing Separating Contracts

The terms of contract $C_{H}^{* *}$ yield a payoff of some $y(A)$ dollars in the success state and nothing in the failure state. Meanwhile, contract $C_{L}^{* *}$ requires that agents deposit their money with the bank in consideration. At the end of the period, bank pays a regular $R A$ plus an extra $x(A)$ dollars. ${ }^{17}$ This is nothing but a higher interest payment to low-type agents to prevent them applying to the loans designed for high-type agents who provide effort. Since low-type agents have to be indifferent between the two contracts

$$
p_{L} y(A)=R A+p^{e} w+x(A) .
$$

Moreover, this contract has to yield zero expected profits to banks in Bertrand competition. Assume there are $n$ such contracts offered in the market. Then, the zero profit condition is given by

$$
\frac{1}{n} h p_{H}(\pi(w)-y(A))-\frac{1}{n}(1-h) x(A)=\frac{1}{n} h R(I-A)+\frac{1}{n} R(1-h) x(A) .
$$

All terms are multiplied by $1 / n$ since agents choose one of the contracts with equal probabilities by Assumption 2. The first term on the left-hand side of (18) is the total repayment of high-type agents in expected terms, whereas the second term is the payment to low-type agents to keep them out of the loan market. $x(A)$ is indeed a pure informational rent that goes to low-type agents and is financed by high-type agents who provide effort. The right-hand side of the equation shows the cost of funds for banks. The first term is the cost of funds that are provided as loans to effort-providing high-type agents, and the second is the cost of funds that are given to low-type agents as informational rents. Solving (17) and (18) for $x(A)$ and $y(A)$ yields the form of the contracts for any wealth level between $\left[A_{L}, \tilde{A}\right]$ :

$$
\boldsymbol{C}^{* *}(A) \equiv\left[\begin{array}{c}
C_{H}^{* *} \\
C_{L}^{* *}
\end{array}\right]=\left[\begin{array}{cc}
D_{H}^{S}(A) & D_{H}^{F}(A) \\
D_{L}^{S}(A) & D_{L}^{F}(A)
\end{array}\right]=\left[\begin{array}{cc}
\frac{p_{L} \pi(w)-R A-p^{e} w-x(A)}{p_{L}} & 0 \\
-R A-x(A) & -R A-x(A)
\end{array}\right],
$$

\footnotetext{
${ }^{17}$ This scheme is similar to the bank promotions in which they promise to deposit $\$ 20$ to the account of the individual if individuals open a savings account with them. However, their motive for this is different.
} 
where

$$
x(A)=\frac{h\left[p_{H} \pi(w)-\frac{p_{H}}{p_{L}} p^{e} w-R I-\left(\frac{p_{H}}{p_{L}}-1\right) R A\right]}{(1-h)(1+R)+h \frac{p_{H}}{p_{L}}} .
$$

A Nash player would still deviate from $\boldsymbol{C}^{* *}(A)$ simply by canceling $C_{L}^{* *}$. Given that all other banks are offering $\left(C_{H}^{* *}, C_{L}^{* *}\right)$, all low-type agents go to these banks, and the deviating bank would enjoy profits since only effort-providing high-type agents apply to it for loans. However, such a deviation would not occur with Wilson players since they are nonmyopic rationals. A potential deviant knows that once other banks cancel $C_{L}^{* *}$, it will incur losses. So, it would not deviate in the first place. ${ }^{18}$ Wilson (1977) explains how this kind of expectation can arise in reality. ${ }^{19}$

Unlike the conventional separating equilibria, here low-type agents become workers but are still cross-subsidized by effort-providing high-type agents who actually become entrepreneurs. Moreover, in contrast to the pooling contracts in which the cross-subsidization is within entrepreneurship, here the cross-subsidization is between the occupations. Literally, low-type agents earn informational rents on their deposits. I record this result in the following proposition.

Proposition 2 (Occupational Cross-subsidies) Low-type agents with wealth levels between $\left[A_{L}, \tilde{A}\right]$ gather informational rents even though they stay inactive in the loan market and become workers. This rent is financed by high-type agents who become entrepreneurs.

Proof. The first part of the result follows directly from (19) and the second part is due to Lemma 1.

\subsection{The agents' problem}

Having analyzed the various kinds of contract offers made by banks, I now focus on the decisions of agents. I assume that if agents had enough wealth to self-finance their firms, it would be profitable for high-type agents who provide effort but not for low-type agents. This also means that the economic activity of low-type agents is socially inefficient. However, they may still want to become entrepreneurs to make use of cross-subsidization in the loan market induced by pooling contracts. The assumption below formalizes these statements by determining the net present value (NPV) of the projects.

Assumption 3 (NPV of Projects) $p_{H} \pi(w)-e>p^{e} w+R I>p_{L} \pi(w)>p^{e} w+\left(p_{L} / \bar{p}\right) R I$.

\footnotetext{
${ }^{18}$ Remember that this equilibrium can be supported as PBE of a sequential game as explained in Section 4.1 . If one does not buy this equilibrium concept, one is left with nonexistence. As an alternative solution to this nonexistence problem, I could impose a Nash equilibrium concept and restrict the strategy space to loan contracts only. Then, the rents are gathered by banks in the form of positive profits rather than low-type and shirking high-type agents, and the equilibrium contract would be given by $\left(C_{1}, C_{2}\right)$ in Figure 3 . Whether I impose a Bertrand-Nash or a Bertrand-Wilson equilibrium concept, neither the nature of the model nor the main results of this paper changes. There is still a fixed pool of entrepreneurs and the problem is still how to increase the number of effort-providing high-type agents in this pool.

${ }^{19} \mathrm{~A}$ recent advertisement of a bank also confirms such expectations. A copy of the advertisement is available upon request.
} 
Note that Assumption 3 asserts that the cost of effort is low enough such that providing effort is profitable for an effort-providing high-type agent (e.g., $\left.\left(p_{H}-p_{L}\right) \pi(w)>e\right)$. I also make the assumption that the cost of effort is not too low.

Assumption 4 (Cost of Effort) $e>\left(p_{H}-p_{L}\right) w$.

This assumption is needed for existence in the general equilibrium. Reorganizing it gives $p_{L} w>$ $p_{H} w-e$. From an ex ante point of view, this means that the opportunity cost of an entrepreneur forgone by not hiring himself as a worker in his firm is higher when he shirks than when he provides effort.

Before solving the agents' problem, I shall note that there has to be maximum self-finance in equilibrium. The reason is that low-type agents can become entrepreneurs only with contracts that require cross-subsidization. If all types have an incentive to apply for loans, high-type agents who provide effort have to cross-subsidize the low-type agents. As indicated in de Meza and Webb (1987), in such a case, they would prefer to self-finance themselves as much as possible since selffinancing has better terms than any cross-subsidizing contract offered by banks. This, in turn, implies that if there are agents who are not using all of their wealth in their firms, they must be either low-type or shirking high-type agents. However, this is inconsistent with the equilibrium, in the sense that banks would not offer the same pooling contract to them but a different one that discourages them from applying for loans. This means that all agents use their wealth in their firms. This also guarantees that simultaneously borrowing and lending makes no difference.

To start, consider the agents' problem given that pooling contracts that make zero profits are offered by banks. For a given $R$ and $w$, high-type agents would like to become entrepreneurs if

$$
p_{H}\left(\pi(w)-\frac{R}{\bar{p}}(I-A)\right)-e>p^{e} w+R A
$$

and they provide effort in entrepreneurship if

$$
p_{H}\left(\pi(w)-\frac{R}{\bar{p}}(I-A)\right)-e>p_{L}\left(\pi(w)-\frac{R}{\bar{p}}(I-A)\right) .
$$

Low-type agents would like to become entrepreneurs if

$$
p_{L}\left(\pi(w)-\frac{R}{\bar{p}}(I-A)\right)>p^{e} w+R A
$$

Solving (21) and (22) for $A$ reveals that high-type agents prefer becoming entrepreneurs if their wealth is higher than a threshold level $A_{H}$, which is defined by

$$
A_{H}:=\frac{p^{e} w-p_{H}\left(\pi(w)-\frac{R}{\bar{p}} I\right)+e}{R\left(\frac{p_{H}}{\bar{p}}-1\right)}
$$

and they provide effort if their wealth is higher than a threshold level $A_{e}$, which is defined by

$$
A_{e}:=I-\frac{\pi(w)-\frac{e}{p_{H}-p_{L}}}{\frac{R}{\bar{p}}} .
$$


In a similar fashion, solving (23) for $A$ reveals that low-type agents prefer to become entrepreneurs if their wealth is lower than a threshold level $A_{L}$, which is defined by

$$
A_{L}:=\frac{p_{L}\left(\pi(w)-\frac{R}{\bar{p}} I\right)-p^{e} w}{R\left(1-\frac{p_{L}}{\bar{p}}\right)} .
$$

This means that low-type agents prefer becoming entrepreneurs only if a significant portion of their firm is financed by the bank. Alternatively, they prefer applying for loans only when they can enjoy large enough cross-subsidies. The situation is different for high-type agents. They prefer self-financing their projects as much as possible since they have to cross-subsidize low-type agents for every penny they borrow. Hence, high-type agents prefer becoming entrepreneurs only if they can self-finance a sufficiently large portion of their project.

It can be shown that $A_{L}>0$ by Assumption 3. In this paper, I neglect some uninteresting cases by assuming that $A_{e}>0$ and that $A_{L}>A_{e}$. The first one rules out the case in which all high-type agents provide effort when they become entrepreneurs, and the second one rules out the case in which there is no adverse selection problem. ${ }^{20}$ Note that $A_{L}>A_{e}$ implies $A_{H}<A_{e}$, which in turn implies that, in principle, there can be high-type agents who would not provide effort had they become entrepreneurs. However, later I show that there cannot be any shirking high-type entrepreneurs in equilibrium. The results that emerge from the above analysis regarding the decisions of agents is summarized in the following proposition.

Proposition 3 (Occupational Decisions) All agents in $\left[0, A_{e}\right]$ prefer becoming workers. All agents in $\left[A_{e}, A_{L}\right]$ prefer becoming entrepreneurs. High-type agents in $\left[A_{L}, I\right]$ prefer becoming entrepreneurs and their low-type counterparts prefer becoming workers.

Proof. See Section 4.3 and Appendix A.

Given the contracts and factor prices in the market, any high-type agent who prefers becoming an entrepreneur provides effort in entrepreneurship and any high-type agent who does not provide effort cannot become an entrepreneur. In $\left[0, A_{e}\right]$, high-type agents do not become entrepreneurs either because they do not want to or because they do not provide effort. However, both of these are induced by the low wealth endowments of the agents in this range. Had they become entrepreneurs, they would have to cross-subsidize low-type agents, which they cannot afford to do at the same time that they provide effort. Hence, they do not provide effort and cannot become an entrepreneur. Nonetheless, with a lower risk-free interest rate, they would be willing to provide effort in entrepreneurship, and this would enable banks to offer loans to them. This intuition forms the base of the policy I propose in Section 6 .

Proposition 4 (Effort Decision) High-type entrepreneurs provide effort in equilibrium.

\section{Proof. See Section 4.3 and Appendix A.}

This result does not follow simply from the assumption on the position of the threshold wealth level $A_{e}$. Wherever $A_{e}$ lies, the average risk of the pool of the applicants under this threshold is $p_{L}$.

\footnotetext{
${ }^{20}$ The analysis of these cases is trivial and left to the reader.
} 
Then, banks offer a lending interest rate of $R / p_{L}$, which effectively discourages shirking high-type agents from entrepreneurship under Assumption 3. From now on, I do not need to distinguish between a high-type entrepreneur and a high-type entrepreneur who provides effort.

\subsection{Lending Interest Rates}

In the previous sections, I derived the contracts offered by banks and analyzed the decisions of agents given these contracts. This section recasts contracts in terms of lending interest rates. This provides an overview of the loan market and allows me to summarize all loan contracts in one figure (which is Figure 6). I begin with showing that the optimal way of financing is debt in this model.

Lemma 2 (Form of Lending Contracts) Whenever agents borrow money from banks, it takes the simple debt form. Moreover, debt is the optimal way of financing in this model.

Proof. The first part of the lemma follows directly from Proposition 1. For the second part, the intuitive proof follows from the fact that low-type agents have more probability weight on the failure state outcome than high-type agents. Thus, they always prefer equity-form contracts. Knowing this, it is not optimal for banks to offer neither equity-form nor a mixture of equityand debt-form contracts. Hence, debt is the optimal way of financing in this model. Technically, the expected payoffs of agents can be ranked in the FOSD sense, and for a two-point payoff distribution, FOSD always implies the monotone likelihood ratio property. It is shown by Innes (1993) that, in this case, with limited liability and risk neutrality, the optimal way of financing has to take the debt form.

By Proposition 1, there can be four different loan applicant pools depending on wealth level. Consider Figure 5. For wealth levels in $\left[0, A_{e}\right]$, high-type agents do not provide effort and banks offer no-effort pooling contracts. Thus, the average risk of the applicant pool in $\left[0, A_{e}\right]$ is indeed $p_{L}$, and the corresponding lending interest rate for these contracts is $R / p_{L}$. Any interest rate below $R / p_{L}$ would incur losses and any interest rate above is undercut by Bertrand competition.

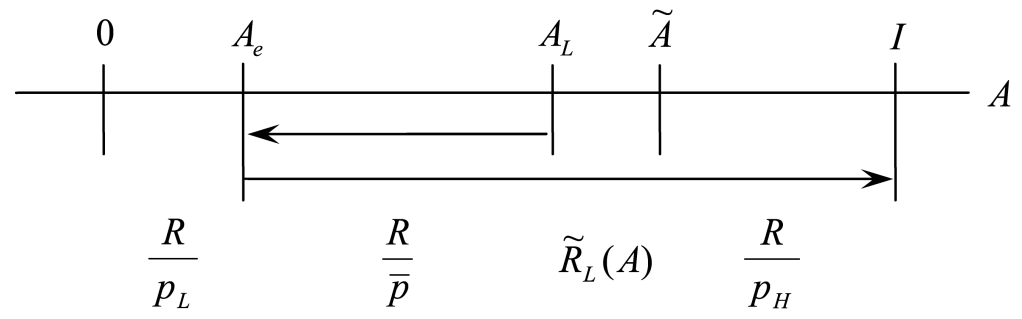

Figure 5: Threshold Wealth Levels

Consider now the wealth levels between $\left[A_{e}, A_{L}\right]$. I have already shown that banks offer crosssubsidizing pooling contracts to these wealth levels. Moreover, high-type agents with these wealth levels provide effort and both types of agents prefer becoming entrepreneurs. The risk of the applicant pool is thus $\bar{p}$, and the corresponding lending interest rate is $R / \bar{p}$. Any interest rate lower than $R / \bar{p}$ incurs a loss for banks, and any interest rate above $R / \bar{p}$ is undercut by the Bertrand competition. 
For wealth levels in $\left[A_{L}, I\right]$, only high-type agents prefer becoming entrepreneurs, and one might be tempted to think that banks should offer the lending interest rate $R / p_{H}$. However, with that interest rate, the participation constraint is violated for some low-type agents whose wealth is slightly above $A_{L}$. That is, they no longer prefer wage-earning to entrepreneurship. Formally, with a lending interest rate of $R / \bar{p}$, the participation constraint of low-type agents with wealth exactly equal to $A_{L}$ is binding:

$$
p_{L}\left(\pi(w)-\frac{R}{\bar{p}}\left(I-A_{L}\right)\right)=p^{e} w+R A_{L}
$$

Now focus on the participation constraint of agents with wealth $A_{L}+\varepsilon$. Given that the lending interest rate offered by banks is $R / p_{H}$, this yields

$$
\begin{aligned}
p_{L}\left(\pi(w)-\frac{R}{p_{H}}\left(I-A_{L}-\varepsilon\right)\right) & \approx p_{L}\left(\pi(w)-\frac{R}{p_{H}}\left(I-A_{L}\right)\right. \\
& >p_{L}\left(\pi(w)-\frac{R}{\bar{p}}\left(I-A_{L}\right)\right) \\
& =p^{e} w+R A_{L} \\
& \approx p^{e} w+R\left(A_{L}+\varepsilon\right) .
\end{aligned}
$$

This means

$$
p_{L}\left(\pi(w)-\frac{R}{p_{H}}\left(I-A_{L}-\varepsilon\right)\right)>p^{e} w+R\left(A_{L}+\varepsilon\right)
$$

and therefore, the participation constraint is violated for low-type agents within the band $\left[A_{L}, \tilde{A}\right]$, where $\tilde{A}$ is defined by ${ }^{21}$

$$
p_{L}\left(\pi(w)-\frac{R}{p_{H}}(I-\tilde{A})\right)=p^{e} w+R \tilde{A} .
$$

The bank cannot offer a lending interest rate of $R / p_{H}$ to the agents within this band. Otherwise, low-type agents would be attracted by the contract in addition to high-type agents. Then what is the lending interest rate in $\left[A_{L}, \tilde{A}\right]$ ? Assume for the moment that the banks offers a loan contract that makes the low-type agents with these wealth levels indifferent between the two occupations. Let $\tilde{R}_{L}(A)$ be such a lending interest rate. A low-type agent is indifferent between the two occupations if

$$
\Upsilon_{L}^{E}(A)=\Upsilon_{L}^{W}(A)
$$

By making use of $(19)$ and $(30), \tilde{R}_{L}(A)$ can be written as

$$
\tilde{R}_{L}(A)=\frac{p_{L} \pi(w)-p^{e} w-R A-x(A)}{p_{L}(I-A)} \quad \forall A \in\left[A_{L}, \tilde{A}\right],
$$

where $\partial \tilde{R}_{L}(A) / \partial A<0$ and $\lim _{A \rightarrow I} \tilde{R}_{L}(A)=-\infty .^{22}$

Given this contract, I now check if there is any deviation contract in any wealth level between $\left[A_{L}, \tilde{A}\right]$. By Assumption 1, low-type agents choose to become workers when they are indifferent

\footnotetext{
${ }^{21}$ Note that Assumption 3 guarantees that $\tilde{A}<I$. Combining this with $0<A_{L}<\tilde{A}$ yields $0<A_{L}<\tilde{A}<I$.

${ }^{22}$ Note that there is also $\hat{R}_{L}(A)$ in Figure 6. $\quad \tilde{R}_{L}(A)$ is defined when the low-type agents earn information rents with cross-subsidizing separating contracts whereas $\hat{R}_{L}(A)$ is the similar interest rate with pooling contracts. $\hat{R}_{L}(A)$ equals to $\left(p_{L} \pi(w)-p^{e} w-R A\right) /\left(p_{L}(I-A)\right)$.
} 
between the two occupations. Start with the case in which all banks offer the lending interest $\tilde{R}_{L}(A)$ and one bank deviates by offering an interest rate just below it. That deviation contract would attract both high- and low-type agents. When both types of agents with these wealth levels apply for loans, nonnegative profits are possible only with an interest rate higher than or equal to $R / \bar{p}$. Therefore, any interest rate below $\tilde{R}_{L}(A)$ is loss making. Given that the interest rate offered by the other banks is $\tilde{R}_{L}(A)$, none of the banks would want to deviate by offering a higher interest rate since none of the agents would be attracted by that contract. Then, banks offer $\tilde{R}_{L}(A)$ in $\left[A_{L}, \tilde{A}\right]$.

Finally, focus on the wealth levels between $[\tilde{A}, I]$. Any loan applicant with these wealth levels must be a high-type agent since none of the low-type agents prefer becoming entrepreneurs in these wealth classes. The equilibrium lending interest rate is then $R / p_{H}$. Any interest rate below $R / p_{H}$ is loss making, and any interest rate above is undercut by Bertrand competition. All of these results are recorded in the following remark.

Remark 1 (Lending Interest Rates) Banks offer a lending interest rate of $R / p_{L}$ in $\left[0, A_{e}\right]$, $R / \bar{p}$ in $\left[A_{e}, A_{L}\right], \tilde{R}_{L}(A)$ in $\left[A_{L}, \tilde{A}\right]$, and $R / p_{H}$ in $[\tilde{A}, I]$, where $\tilde{A}$ is defined by

$$
\tilde{A}:=\frac{p_{L}\left(\pi(w)-\frac{R}{p_{H}} I\right)-p^{e} w}{R\left(1-\frac{p_{L}}{p_{H}}\right)}>0 .
$$

Note that the lending interest rate is a mark-up on the cost of loanable funds. For wealth levels between $\left[0, A_{L}\right]$ and $[\tilde{A}, I]$, the mark-up is constant and directly associated with the risk of the loan applicant pool. It is still associated with the risk of the pool in $\left[A_{L}, \tilde{A}\right]$, but it also depends on wealth levels. It also bears mentioning that in $\left[A_{L}, \tilde{A}\right]$ banks follow a limit pricing strategy for the loans by making low-type agents indifferent between the two occupations. Nonetheless, as discussed before, banks give information rents to low-type agents to keep them inactive in the loan market in these contracts.

\subsection{Endogenous wealth classes}

An overview of the market is shown in Figure $6 . \hat{R}_{L}(A)$ is the lending interest rate that makes low-type agents indifferent between the two occupation with a pooling contract. $\tilde{R}_{L}(A)$ is the similar interest rate with a cross-subsidizing separating contract. ${ }^{23}$ Banks offer pooling contracts under $A_{L}$ and separating contracts over it. The equilibrium lending interest rates, indicated in Remark 1, are shown with bold lines in the figure. The contractual structure in the lending market endogenously forms four different wealth classes in the economy: the poor, the lower-middle, the upper-middle, and the rich class.

The poor class agents are the ones whose wealth levels are in between $\left[0, A_{e}\right]$. They are all isolated from the loan market owing to the facts that only pooling contracts can be offered and that high-type agents do not provide effort in entrepreneurship in this wealth class. If they do not provide effort, their success probability in entrepreneurship is the same as the success probability of low-type agents. This makes banks offer an interest rate of $R / p_{L}$ to the poor class, which is

${ }^{23}$ The wedge between them is a measure of the informational rents that go to low-type agents. 
sufficient to discourage all poor agents from applying for loans and becoming entrepreneurs. So, the source of the market failure in the poor class is the downward distortion of the occupational decisions. That is, high-type agents in the poor class do not become entrepreneurs because of wealth constraints.

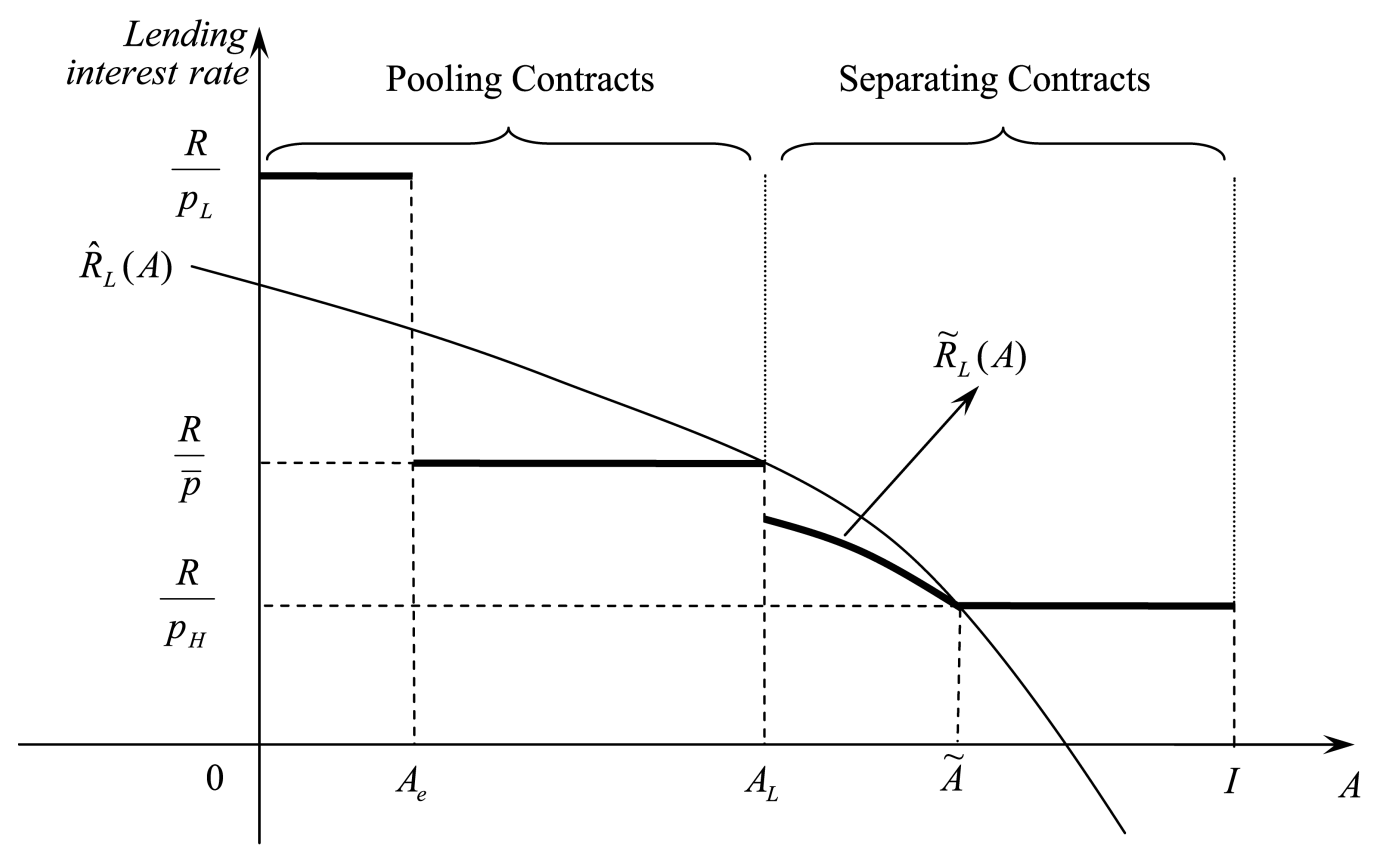

$\begin{array}{cccc}\text { Poor } & \text { Lower-middle } & \text { Upper-middle } & \text { Rich } \\ \text { H: worker } & \text { H: entrepreneur } & \text { H: entrepreneur } & \text { H: entrepreneur } \\ \text { L: worker } & \text { L: entrepreneur } & \text { L: worker } & \text { L: worker }\end{array}$

Figure 6: Overview of the Market

I call the wealth class $\left[A_{e}, A_{L}\right]$ the lower-middle class. As in the poor class, banks are able to offer this wealth class only pooling contracts. However, now the source of the market failure is the upward distortion of the occupational decisions. The fact that high-type agents cannot be distinguished from low-type agents results in a situation where low-type agents are attracted to the bank loans. Consequently, both types of agents become entrepreneurs in the lower-middle wealth class, and the high-type members of this wealth class cross-subsidize their low-type counterparts. The cross-subsidies are within entrepreneurship in this wealth class.

The wealth class in $\left[A_{L}, \tilde{A}\right]$ is the upper-middle class. In this class, banks are able to offer separating contracts. As a result, low-type agents become workers and high-type agents become entrepreneurs. As I have shown before, high-type agents still need to cross-subsidize low-type agents in the loan market. However, this time the cross-subsidies are between the occupations.

Finally, I call the wealth class in $[\tilde{A}, I]$ the rich class. They do not need to borrow as much to be able to become entrepreneurs. This means that the low-type agents do not benefit from the cross-subsidies to the same extent as the low-type agents with lower wealth levels. Thus, they are not attracted to the bank loans even when banks offer an efficient contract with an interest rate of $R / p_{H}$. Then, they all become workers whereas their high-type counterparts become entrepreneurs. These contracts do not entail any cross-subsidies among loan applicants. 
An important point to note is that none of the entrepreneurs have incentives to destroy their wealth to be able to get a loan in a poorer wealth class. This can be understood simply from the derivation of equilibrium contracts in Section 4.2 which shows that equilibrium contracts for higher wealth levels are associated with higher iso-profit lines for entrepreneurs.

\subsection{Entrepreneurship and economic development}

It is known as a stylized fact that entrepreneurship is better in developed countries than in developing countries. This section provides one explanation for this. Figure 6 reflects the fact that adverse selection hits the economy at relatively lower wealth levels: in the poor class (i.e., $\left.A \in\left[A_{e}, A_{L}\right]\right)$ and the lower-middle class (i.e., $\left.A \in\left[A_{e}, A_{L}\right]\right)$. The cross-subsidies do not change with the wealth level in these wealth classes. In the upper-middle class (i.e., $A \in\left[A_{L}, \tilde{A}\right]$ ), there are transfers between occupations in the form of efficient information rents. However, there is no adverse selection problem in this class since these transfers do not distort the occupational decisions. Moreover, cross-subsidies decrease with wealth level and ultimately become zero at $\tilde{A}$. Finally, there is no problem in both the occupational decisions and the pricing of the loans in the rich class (i.e., $A \in[\tilde{A}, I]$ ).

These contractual differences between wealth classes provide some insights into the phases of development in economies. If there are more people in the poor and the lower-middle classes in a developing country than in a developed country, the adverse selection should be more of an issue for the former. As agents start accumulating wealth, more and more of them are expected to move from the poor and the lower-middle classes to the upper-middle and the rich classes. Thus, in the development process of an economy, the problems in the entrepreneurial sectors erected by adverse selection become less and less severe since some of them turn into transfers between occupations in the form of efficient information rents (as in the upper-middle class) or completely disappears (as in the rich class). This is at least one reason why the entrepreneurial sectors of the developed countries are better.

The thresholds $A_{e}, A_{L}$, and $\tilde{A}$ are presumably different in different countries. However, the intuition still applies. What matters in general is whether there are relatively more people in the poor and the lower-middle classes in which adverse selection distorts occupational decisions. In this model, it happens in relatively lower wealth classes; but this seems realistic, too. In such situations, implementing the labor market policies I propose in this paper becomes more compelling. This result is consistent with the GEM's public policy prescription that poor countries should focus on improving the general business environment before focusing exclusively on entrepreneurs. In particular, the GEM suggests that the family income (which can be interpreted as wage-subsidies in the model of this paper) should be increased. Section 5.3 discusses some other stylized facts.

\section{General Equilibrium}

The analysis so far has focused on the partial equilibrium in which the wage and the risk-free interest rates are given. This section carries the analysis to a general equilibrium by endogenizing the wage and the risk-free interest rates. The purpose of the general equilibrium analysis is two fold. First, it shows that there are economies in which the assumptions of the previous sections 
are satisfied. ${ }^{24}$ Second, for the various reasons explained earlier, this paper conducts the public policy analysis when the labor and credit markets are interrelated.

In this section, I modify the equilibrium definition slightly to allow for market clearing conditions. Let $E$ be the number of entrepreneurs in the economy. Denoting the equilibrium values of variables with asteriks, the equilibrium is defined as follows.

Definition 2 (Equilibrium Concept) Assume that banks are nonmyopic Bertrand-Wilson players following pure strategies. An equilibrium is a quadruple $\boldsymbol{\Delta}=\left(R^{*}, w^{*}, p^{e *}, E^{*}\right)$ such that banks earn nonnegative profits in every wealth level. There is no new set of contracts that could earn higher profits even after the elimination of all unprofitable set of contracts. In an equilibrium, both credit and labor markets clear.

\subsection{Equilibrium conditions}

As indicated in Definition 2, an equilibrium is characterized by the quadruple $\boldsymbol{\Delta}$. It still needs to be incentive compatible and individually rational, and it is still the case that proper participation constraints must hold in an equilibrium. I have already imposed them in partial equilibrium. Below I analyze the remaining equilibrium conditions to solve for the quadruple $\boldsymbol{\Delta}$ under Assumption 3.

By Proposition 3, the number of high-type entrepreneurs, $E_{H}$, and the number of low-type entrepreneurs, $E_{L}$, are given by

$$
\begin{aligned}
E_{H}(R, w) & =h\left[1-G\left(A_{e}(R, w)\right)\right] \\
E_{L}\left(R, w, p^{e}\right) & =(1-h)\left[G\left(A_{L}\left(R, w, p^{e}\right)\right)-G\left(A_{e}(R, w)\right)\right]
\end{aligned}
$$

respectively. The total number of entrepreneurs in the economy, $E$, is then given by

$$
E\left(R, w, p^{e}\right)=E_{H}(R, w)+E_{L}\left(R, w, p^{e}\right)
$$

The weighted average of the success probabilities of all entrepreneurs in the economy, $p^{e}$, is given by

$$
p^{e}=\frac{p_{H} E_{H}(R, w)+p_{L} E_{L}\left(R, w, p^{e}\right)}{E\left(R, w, p^{e}\right)} .
$$

Workers are the source of the loanable funds in the economy and entrepreneurs are the ones who demand loans. The credit market clears when the demand for credit equals to the supply of credit. There are $E$ entrepreneurs, each of which uses $I$ units of capital. Therefore, $E I$ has to be equal to the aggregate wealth available in the economy, $\bar{A}$, or:

$$
E=\frac{\bar{A}}{I}
$$

This means that the number of entrepreneurs in the economy is equivalent to the aggregate wealth available in the economy divided by the project size, and thus, is fixed. As the number

\footnotetext{
${ }^{24}$ In that sense, I do not solve for the full-blown general equilibrium, but this is sufficient for my purpose of showing that efficiency might require taxing entrepreneurs.
} 
of entrepreneurs, $E$, is fixed, the number of workers, $1-E$, is also fixed. Any policy provided in this model cannot change these numbers, which allows me to focus exclusively on the quality of entrepreneurs. That is, what matters in this model is not the size of the set $E$, but its composition $\left(E_{H}+E_{L}\right)$. It bears mentioning here that Gale (1991) finds that credit subsidies appear to have important effects on the allocation of credit but do not change the aggregate economic activity. This is consistent with the credit market clearing condition here. Moreover, Raynold (1995) shows that credit subsidies do not have a positive effect on output. Thus, success taxes may be needed instead of credit subsidies.

Notice that the fixed number of entrepreneurs and workers does not mean that the credit supply to the banking system is fixed. It can change as a result of a change in the composition of the entrepreneurs in the economy. For example, if you swap a rich low-type entrepreneur with a poor high-type worker, the supply of loans to banks increases even though the number of entrepreneurs remains the same. As I show later, the policy can change who owns the funds and who supplies them in a way that increases the loan supply to banks. This, in turn, decreases the risk-free and the lending interest rates. Then, it is sufficient to show that this can improve the selfselection in the economy. Oftentimes this is taken to require extreme policies (such as complete redistribution), whereas I show in this paper that a small tax and subsidy policy can improve the economy extensively by influencing the occupational choice of agents in different wealth classes.

Finally, the labor demand by each entrepreneur is

$$
l=l(w):=f^{\prime-1}(w) .
$$

The labor market clears when the aggregate supply of labor by workers equals the aggregate demand for labor by entrepreneurs. There are $E(w)$ entrepreneurs and $1-E(w)$ workers. Each entrepreneur demands $l(w)$ workers. Thus, the labor market clears when $E(w) l(w)=1-E(w)$. This boils down to

$$
E(w)=\frac{1}{1+l(w)} .
$$

\subsection{Equilibrium}

Eqs. (34), (35), (36), and (38) form a system of four equations in four unknowns, namely $R, w, p^{e}$, and $E$. Moreover, this system has a separable structure. First, eqs. (36) and (38) form a module from which $E^{*}$ and $w^{*}$ can be found. Then, after substituting for $E^{*}$ and $w^{*}$, eqs. (34) and (35) give $R^{*}$ and $p^{e *}$.

\subsection{The number of entrepreneurs and the wage rate}

One point of concern is whether there is a unique equilibrium in the $w-E$ module of separable system of equations. The next proposition rules out the possibility of multiple equilibria under the plausible assumptions of Section 3.5 on the production function.

Proposition 5 (Uniqueness - w) Assume the production function is strictly concave and satisfies Inada conditions. Then, there exists a unique wage rate of $w^{*}$. 
Proof. It has to be true that $f^{\prime}(l)-w=0$. Then, by implicit differentiation

$$
\frac{\partial l(w)}{\partial w}=-\frac{\frac{\partial\left(f^{\prime}(l)-w\right)}{\partial w}}{\frac{\partial\left(f^{\prime}(l)-w\right)}{\partial l}}=\frac{1}{f^{\prime \prime}(l)}>0 \text { since } f^{\prime \prime}(l)<0 \text { by strict concavity. }
$$

One of the Inada conditions asserts that $\lim _{l \rightarrow \infty} f^{\prime}(l)=0$. This condition implies $\lim _{w \rightarrow 0} l(w)=\infty$. On the other hand, (38) yields

$$
\frac{\partial E(w)}{\partial w}=-\frac{\frac{\partial l(w)}{\partial w}}{(1+l(w))^{2}}
$$

Since $\partial l(w) / \partial w<0, E(w)$ is an increasing function, and $\lim _{w \rightarrow 0} l(w)=\infty \operatorname{implies} E(0)=0$. Then, (36) has to cut (38) once and only once.

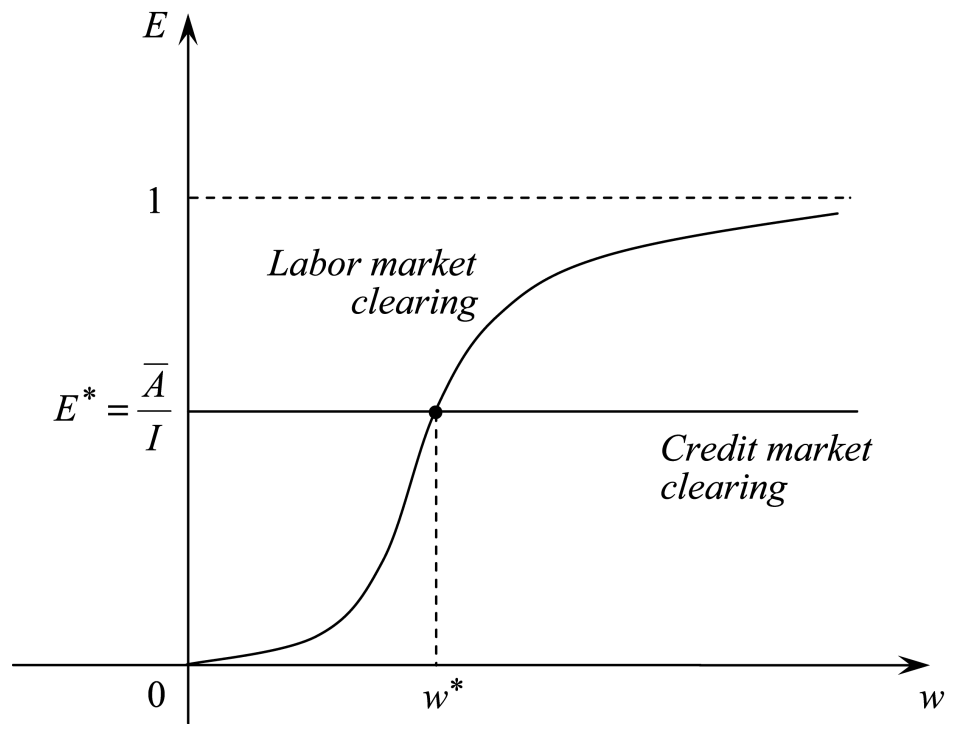

Figure 7: The Number of Entrepreneurs and the Wage Rate

Figure 7 shows the uniqueness of the wage rate graphically. An increase in the aggregate wealth available in the economy results in an increase in the wage rate, too. This implies that higher wages are associated with developed countries and lower wages are associated with developing countries, which is consistent with the stylized facts listed in Lloyd-Ellis and Bernhardt (2000). ${ }^{25}$ Figure 7 depicts another important relation between the number of entrepreneurs and the wage rate. An increase in the number of entrepreneurs cannot occur without an increase in the wage levels. ${ }^{26}$ This is consistent with the policy prescription of the GEM that underlines the fact that,

\footnotetext{
${ }^{25}$ An objection to this reasoning could be that the average project size in different countries could be different. It is certainly true, but still the same intuition applies due to the fact that everything is scale invariant in terms of investment in this model. Therefore, all results can be interpreted per unit of investment. This requires scaling the wealth distribution to take that into account, which can be done without affecting the results. Then, I can write the production function in the intensive form as is done for any neoclassical constant returns to scale production function. The only difference is, this time, everything is written per unit of investment rather than per unit of effective labor. Then, $f(l)$ is indeed in the intensive form, and there is no loss of generality in interpreting $\bar{A} / I$ in Figure 7 as aggregate wealth per unit of investment rather than aggregate wealth divided by fixed project size.

${ }^{26}$ By looking at the curve in Figure 7, one should not make the conclusion that the number of workers is inversely related to the wage rate in the economy. This curve is neither the labor supply nor the labor demand curve. It is just an equilibrium condition derived in (38) that takes into account both labor supply and demand.
} 
to improve the entrepreneurial sectors, developing countries (almost all of which have lower wage levels) should design policies that enhance the growth of family incomes.

\subsection{Possible equilibria in the general equilibrium}

Assumption 3 asserts that the NPV of the projects of high-type agents is positive and that of low-type agents is negative in equilibrium. Thus, low-type agents have socially inefficient projects but may still apply for loans due to cross-subsidizing pooling contracts. The analysis here tries to find ways of improving the average success probability of the pool of entrepreneurs and the welfare in such situations. The first point of concern is whether there is any equilibrium satisfying the assumptions imposed in partial equilibrium. The following lemma shows that, for every given wage rate, there exists a triangular subspace in which my assumptions are satisfied, and that therefore, such an equilibrium is not measure zero.

Lemma 3 (Equilibrium Subspace) $\forall w^{*} \exists(A \stackrel{\triangle}{B C})$ in which Assumption 3, Assumption 4, and $0<A_{e}<A_{L}$ are satisfied.

Proof. See Appendix B.1.

I make the policy analysis under the assumption that the equilibrium occurs in the triangle $(A B C)$. There are, of course, other settings with respect to the NPV of the projects. When the NPVs of projects of both types are negative, none of the banks would provide loans to them. This is inconsistent with the equilibrium since firms (or entrepreneurs) are necessary for production, and therefore, factor prices must adjust. When the NPVs of projects of both types are positive, both types prefer becoming entrepreneurs regardless of their wealth level and banks would be willing to provide loans to them. This is also inconsistent with the equilibrium since labor is necessary for production, and thus, factor prices must adjust.

\subsection{Interest rates and the average success probability}

I have already found the equilibrium number of entrepreneurs $E^{*}$, and the equilibrium wage rate $w^{*}$. Putting these into (34) and (35) and solving for $R$ and $p^{e}$ gives the equilibrium level of risk-free interest rate, $R^{*}$, and the equilibrium level of the average success probability of entrepreneurs in the economy, $p^{e *}$.

To simplify, after substituting for $E^{*}$ and $w^{*}$ in (34) and (35), I solve for $E_{H}$ and $E_{L}$, and get

$$
\begin{aligned}
E_{H}\left(R, w^{*}\right) & =\left(\frac{p^{e}-p_{L}}{p_{H}-p_{L}}\right) \frac{\bar{A}}{I} \\
E_{L}\left(R, w^{*}, p^{e}\right) & =\left(\frac{p_{H}-p^{e}}{p_{H}-p_{L}}\right) \frac{\bar{A}}{I} .
\end{aligned}
$$


I define the following functions from (39a) and (39b):

$$
\begin{aligned}
\phi_{H}\left(R, p^{e}\right) & :=E_{H}\left(R, w^{*}\right)-\left(\frac{p^{e}-p_{L}}{p_{H}-p_{L}}\right) \frac{\bar{A}}{I}=0 \\
\phi_{L}\left(R, p^{e}\right) & :=E_{L}\left(R, w^{*}, p^{e}\right)-\left(\frac{p_{H}-p^{e}}{p_{H}-p_{L}}\right) \frac{\bar{A}}{I}=0 .
\end{aligned}
$$

$\phi_{H}\left(R, p^{e}\right)=0$ defines $R$ as an implicit function of $p^{e}$ by taking into account only high-type agents. Call this the high-type locus. $\phi_{L}\left(R, p^{e}\right)=0$ does the same thing taking into account only low-type agents. Call this the low-type locus. It can be shown that the high-type locus is always downward sloping in $(A B C)$ but that the low-type locus can be downward or upward sloping. Therefore, whenever the low-type locus is upward sloping, an equilibrium has to be unique if one exists. The next proposition proves this formally.

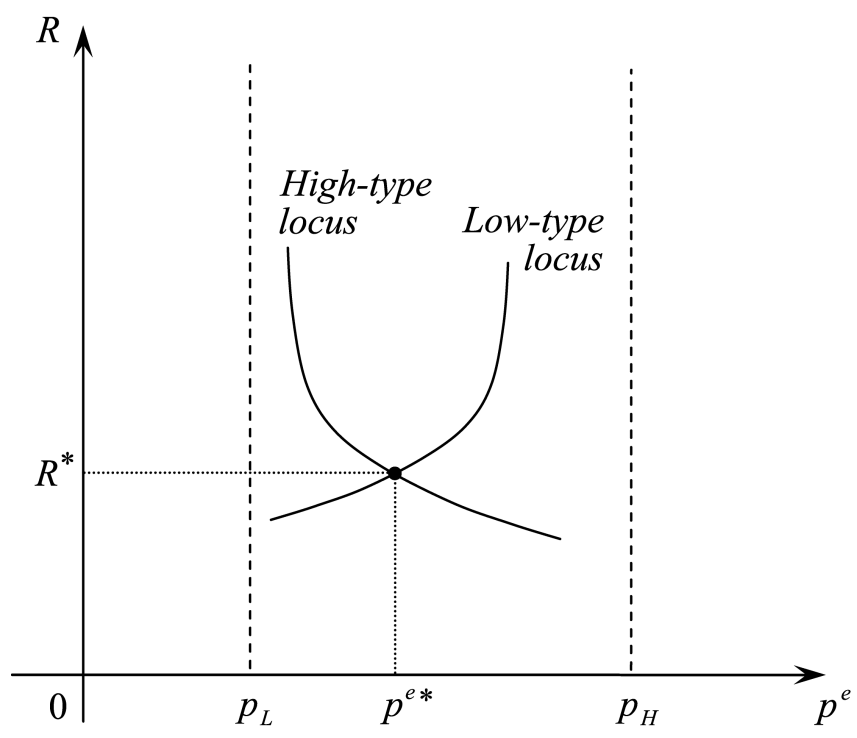

Figure 8: The Risk-free Interest Rate and the Average Success Probability

Proposition 6 (Uniqueness of $R$ and $p^{e}$ ) For a large class of economies, if an equilibrium exists, it is unique in $R^{*}$ and $p^{e *}$.

Proof. See Appendix B.2.

Figure 8 illustrates high-type and low-type loci when the latter is upward sloping. In this regime, as far as the high-type locus is concerned, more and more high-type agents would enter into entrepreneurship when the interest rate decreases gradually. This, in and of itself, will increase the average success probability of entrepreneurs in the economy. Going against is the low-type locus. As far as this locus is concerned, when the interest rate decreases gradually, more and more low-type agents would enter into entrepreneurship. This gradually decreases the average success probability. The equilibrium occurs where these two opposing forces meet.

Corollary 1 (Uniqueness of $\boldsymbol{\Delta}$ ) For a large class of economies, if a general equilibrium exists, it is defined with a unique and stable quadruple $\boldsymbol{\Delta}=\left(R^{*}, w^{*}, p^{e *}, E^{*}\right)$. 
Proof. This result follows directly from Proposition 5 and Proposition 6.

\section{Success Taxes and Wage Subsidies}

This section carries out the policy analysis. ${ }^{27}$ The government cannot distinguish between types any better than the banks can. Nonetheless, it can design policies to improve the welfare, which is defined in this paper to be total expected output of the economy. The only reason that lowtype agents would like to become entrepreneurs in this model is that the types are hidden, and thus, they may get loans with better terms than they would have gotten if there were perfect information. This results in downward distortions in the occupational decisions of the poor class and upward distortions in the occupational decisions of the lower-middle class. These distortions negatively affect who uses the capital, and hence, prevents the economy from better outcomes. The government should design a tax-subsidy policy that can better inform the economy about the types upon implementation. Given the information structure, this is possible only if self-selection improves in the economy.

A policy that increases the quality of the pool of entrepreneurs in the economy is sufficient to increase the expected output. When $p^{e}$ is increasing, that means the number of high-type entrepreneurs is increasing, too. This also means that the number of low-type entrepreneurs is decreasing since the total number of entrepreneurs in the economy is fixed. As a result, total expected output increases. Then, the government's problem is how to change the thresholds $A_{e}$ and $A_{L}$, which are endogenously determined in the general equilibrium, in such a way that the welfare increases.

It is better for the society if a low-wealth high-type worker becomes an entrepreneur instead of a high-wealth low-type entrepreneur. This is desirable not only because high-type agents have higher success probabilities (and thus, can produce more) but also because the supply of loanable funds to the financial intermediation increases when that happens (which eventually decreases the cost of loans). I shall focus on a policy in which the government gives small wage subsidies to workers and finances them by small taxes on entrepreneurs that are paid only in a success state. In that case, the problem to be solved by agents (who may become entrepreneurs with pooling contracts) is modified in the following way:

$$
\begin{aligned}
p_{H}\left(\pi(w)-t-\frac{R}{\bar{p}}(I-A)\right)-e & \lesseqgtr p^{e}(w+s)+R A \\
p_{L}\left(\pi(w)-t-\frac{R}{\bar{p}}(I-A)\right) & \lesseqgtr p^{e}(w+s)+R A
\end{aligned}
$$

for a high- and a low-type agent, respectively. Here, $t$ is the tax on entrepreneurs, and $s$ is the wage subsidy to workers, both of which are assumed to be very small. The government operates under a balanced budget regime, and hence, uses all of the tax revenue to finance wage subsidies

\footnotetext{
${ }^{27}$ For the sake of highlighting the result, the analysis below focuses on the economies characterized by the two curves shown in Figure 8. A tax on entrepreneurs may still be desirable even when the low-type locus is downward sloping. One case in which a tax on entrepreneurs is desirable is sufficient to make the point of this paper.
} 
to workers. Then, the relationship between $t$ and $s$ is given by

$$
s=\frac{\bar{A}}{I-\bar{A}} t
$$

After substituting for $s,(40 \mathrm{a})$ and (40b) are now given by $\phi_{H}\left(R, p^{e}, t\right)$ and $\phi_{L}\left(R, p^{e}, t\right)$, and thus, both high-type and low-type loci become functions of not only $p^{e}$ but $t$ as well. I start off with determining the effects of the tax-subsidy policy on these loci.

Proposition 7 (Policy - Loci) The tax-subsidy policy shifts both high-type and low-type loci down.

Proof. See Appendix B.3.

Corollary 2 (Policy - Lending Interest Rate) The lending interest rate for every contract decreases.

Proof. The result follows directly from Proposition 7. If both loci shift down, the risk-free interest rate - which is nothing but the cost of loanable funds - must decrease. If the cost of loanable funds decreases then lending interest rates in every wealth level must decrease as well.

The change in the equilibrium level of the risk-free interest rate is determinate as shown in Corollary 2. However, the change in the equilibrium level of average success probability of entrepreneurs in the economy, $p^{e}$, is ambiguous, and in general, depends on the wealth distribution. Banerjee and Newman (1993), and Legros, Newman, and Proto (2006) show how occupational choice and relative scarcity of entrepreneurs and workers, respectively, can be dependent on the initial wealth distributions. Thus, the result that the policy is contingent on the wealth distribution is not surprising. The next proposition characterizes the cases in which the proposed policy increases the equilibrium level of $p^{e}$.

Proposition 8 (Policy) There exist economies in which a small tax on entrepreneurs used to subsidize workers increases the average quality of the entrepreneurs. This policy is welfare improving in such economies.

Proof. See Appendix B.4.

Figure 9 shows a case in which a tax on entrepreneurs used to subsidize workers is increasing the average quality of entrepreneurs. Before the policy, equilibrium is given by the pair $\left(R^{*}, p^{e *}\right)$. After the policy, new loci are given by the dotted curves and the new equilibrium occurs at $\left(R_{\text {tax }}^{*}, p_{\text {tax }}^{e *}\right)$. The rest of this section is devoted to provide the intuition for this result.

Once a small tax on entrepreneurs is imposed, the total cost of starting a firm increases for all entrepreneurs, and as shown in Corollary 2, the lending interest rate decreases. This means that the borrowing costs of all entrepreneurs decreases. Remember that cross-subsidization in the credit market is the only reason that low-type agents attempt to become entrepreneurs. After the policy, the low-type agents cannot enjoy the cross-subsidies in the financial markets to the same 


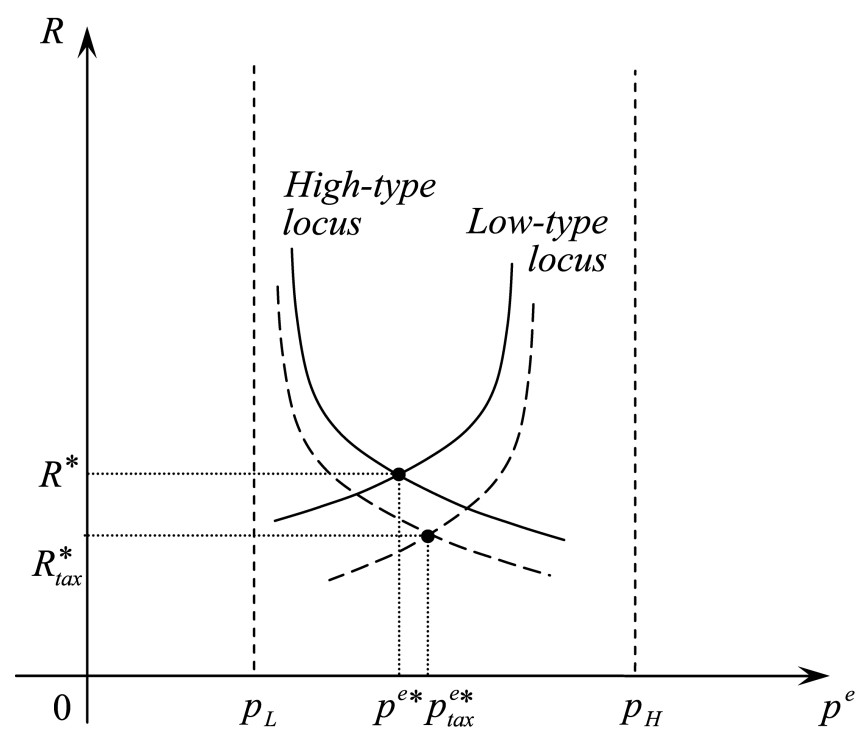

Figure 9: The Tax-Subsidy Policy

extent they had before. The policy converts some of borrowing costs (which are subject to adverse selection) into tax costs (which are not subject to adverse selection), and this disproportionately discourages low-type agents from entrepreneurship.

Which low-type agents changes their decisions from entrepreneurship to wage-earning? As shown in (26), they prefer becoming entrepreneurs when their wealth is less than $A_{L}$. In other words, they become entrepreneurs only if a sufficiently large portion of their investments is financed by banks. Thus, low-type agents who change their occupational decisions in the margin due to a tax must be the ones who have relatively higher wealth. They are the ones who borrow relatively less and enjoy relatively small cross-subsidies. Once the government introduces the tax-subsidy policy they enjoy even less cross-subsidies and some of the richer ones now prefer wage-earning over entrepreneurship.

Since the aggregate wealth is fixed, the number of entrepreneurs is going to be the same before and after the policy. Then, the question is which agents would fill the entrepreneurship positions emptied by richer low-type agents? As shown in (25), high-type agents provide effort in entrepreneurship only if they are sufficiently rich (e.g., if $A>A_{e}$ ). They need to pay cross-subsidies to low-type agents for the part of the investments financed by their bank. A poor high-type agent cannot afford to both provide effort and cross-subsidize low-type agents. Then, among the hightype agents, the ones who switch from wage-earning to entrepreneurship in the margin are the ones who are relatively poor. However, their low-type counterparts can also become entrepreneurs as a result of pooling contracts in the poor class.

Figure 10 illustrates a situation in which the tax-subsidy policy increases $p^{e}$. An increase in $t$ decreases $R$. At the same time, both affect $A_{L}$ and $A_{e}$. Start with the before-the-policy thresholds $A_{e}$ and $A_{L}$. The effects of the tax on the wealth thresholds are given by $\Delta t$, and the effects of changes in $R$ on them are shown by $\Delta R$. Imposing a tax of $t$, in and of itself, shrinks the lowermiddle class by increasing $A_{e}$ and decreasing $A_{L}$. The temporary thresholds in the transition are now given by $A_{e}^{\prime}$ and $A_{L}^{\prime}$. However, the tax will eventually decrease $R$ by increasing the loan supply to the banks. The change in $R$, in turn, widens the lower-middle class by moving the 


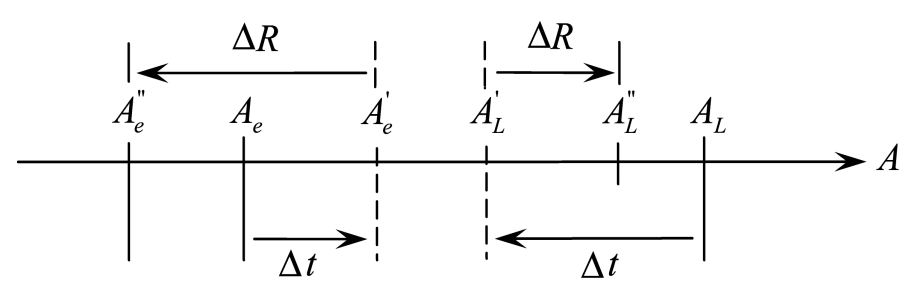

Figure 10: Effects of Changes in $R$ and $t$ on the Wealth Thresholds

thresholds to $A_{e}^{\prime \prime}$ and $A_{L}^{\prime \prime}$.

The overall change in $A_{L}$ is a decrease. On the right side of $A_{L}$ (i.e., in the upper-middle and the rich classes) only high-type agents may become entrepreneurs due to separating contracts. Therefore, the decrease in $A_{L}$ leads to greater separation by getting rid of some low-type agents from entrepreneurship. The overall change in $A_{e}$ is also a decrease. On the left side of this threshold (i.e., in the poor class) high-type agents do not provide effort which consequently isolates them from the loan market. Thus, anyone in this wealth class has no chance but become workers. When $A_{e}$ moves down, more high-type agents can provide effort in entrepreneurship, and thus, banks are able to offer loans to them. However, their low-type counterparts can also become entrepreneurs due to pooling contracts on the right side of $A_{e}$ (i.e., in the lower-middle class).

As a result, some rich low-type entrepreneurs are swapped with an equal number of poor low- and high-type workers. Given a fixed pool of entrepreneurs, the average quality of entrepreneurs must increase in the economy. The fact that the ones who change their decisions from wage-earning to entrepreneurship are relatively poorer than the ones who do the opposite is the reason why the interest rate decreases. This is one possibility in which a tax on entrepreneurs increase the average quality of them. It should be noted that there are other cases in which a subsidy to entrepreneurs is required to increase average quality of them in the economy.

\section{Conclusion}

This paper explores the quality of entrepreneurs in an occupational choice model. The idea I highlight is that the common partial analysis of entrepreneurship might be misleading. Entrepreneurs are not merely the ones who make risky real investments or seek loans; they also create jobs. In addition, wage-earning is the natural outside option to entrepreneurship. A general theory of entrepreneurship should take into account all of these interlinkages between the labor and the credit markets.

I show that, for a large class of economies, it might be desirable to tax entrepreneurs and give the proceeds to workers. By doing so, the government can improve entrepreneurial self-selection. The tax converts some of the cross-subsidies in the financial intermediation into tax revenue, which is then used to finance the wage subsidies. The overall effect of the policy is to exchange some rich low-type entrepreneurs with poor high- and low-type workers. As a result, the average success probability of the entrepreneurs in the economy increases. Given that the aggregate wealth in the economy is fixed, this in turn increases the total expected output of the economy. Since the agents who switch from entrepreneurship to wage-earning are relatively wealthier than the agents who do the opposite, the credit supply to the banking system increases. This decreases the risk-free 
interest rate, which is equal to the cost of loanable funds, as well as the lending interest rate.

It bears mentioning that the policy I propose is a pure efficiency result. That is, in some economies, efficiency requires taxing entrepreneurs and giving the proceeds to workers to improve the welfare. The policy simply changes the threshold levels for wealth classes so as to increase the average quality of active entrepreneurs in the economy. In my view, this pure efficiency result enhances equity as well, since richer low-type entrepreneurs are swapped with poorer high- and low-type workers as a result of the policy.

The model stresses the role of unobserved success probability in the determination of the market outcome. This, of course, leaves out a number of other considerations that may be important. In that sense, the practical implication of this result might not be a tax entrepreneurs. However, as opposed to the common view in the media, it is at least clear that subsidies to entrepreneurs may not mitigate the market failures induced by asymmetric information, and thus, asymmetric information, in and of itself, is not sufficient to justify subsidy policies. Inci (2006) - the web version of the paper - discusses some extensions.

\section{A Appendix: Derivation of Contracts}

\section{A.1 Cross-subsidizing pooling contracts}

Figure 11 illustrates the equilibrium contract offers to agents with wealth levels between $\left[0, A_{L}\right]$. Assume a bank offers the contract $C_{1}$. As can be easily seen from (14a) and (14b), the iso-profit lines of lowtype agents are steeper than those of high-type agents who provide effort. The pair of iso-profit lines for a high-type agent who provides effort and for a low-type agent that pass through the point $C_{1}$ are shown in Figure 11. $C_{1}$ cannot be an equilibrium since there always exists a deviation contract $C_{2}$ at the north-west of $C_{1}$ that is preferable to effort-providing high-type agents but not to low-type agents. Then, any such contract can be undercut unless it is on the $Y^{S}$-axis at a point such as $C_{3}$. However, since $C_{3}$ is below $Z P_{H L}$, it makes positive profits with both types. Then, it cannot be an equilibrium since other banks can undercut it until they make zero profits. This happens at $C^{*}$ where an equilibrium is obtained. The iso-profit lines that pass through $C^{*}$ are denoted by $H H^{\prime}$ and $L L^{\prime}$ for effort-providing high-type agents and for low-type agents, respectively. In contrast to Rothschild and Stiglitz's (1976) classic demonstration of the impossibility of a pooling contract, there cannot be a deviation contract at the north-west of this contract due to limited liability. Any contract outside the first quadrant is a pound of flesh contract that require more payments than the borrower currently has. ${ }^{28}$

Since $C^{*}$ is on $Z P_{H L},(15)$ yields the following form for the pooling contract:

$$
\boldsymbol{C}^{*}(A) \equiv\left[\begin{array}{c}
C_{H}^{*} \\
C_{L}^{*}
\end{array}\right]=\left[\begin{array}{ll}
D_{H}^{S}(A) & D_{H}^{F}(A) \\
D_{L}^{S}(A) & D_{L}^{F}(A)
\end{array}\right]=\left[\begin{array}{cc}
\frac{R(I-A)}{\bar{p}} & 0 \\
\frac{R(I-A)}{\bar{p}} & 0
\end{array}\right]
$$

Banks offer the same contract for all types and they make zero profits. Effort-providing high-type agents'

\footnotetext{
28 "Pound of flesh" is a reference to The Merchants of Venice by William Shakespeare. Bassanio gets a loan from a merchant called Shylock. The price for not repaying is a pound of flesh from his friend Antonio, but it founders on Shylock's inability to cut out exactly a pound. I thank David de Meza for pointing out this example to me. There may be some other non-monetary fines in cases in which the repayment is not made. For example, before the Solonian Constitution, citizens could be sold as slaves when they went bankrupt in Athens.
} 


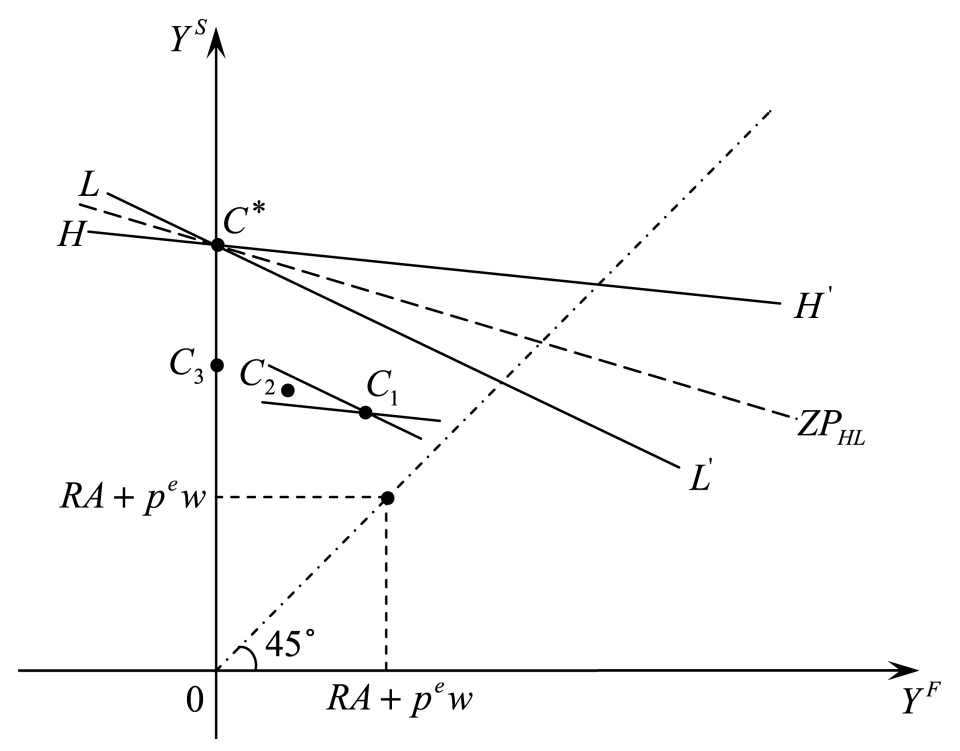

Figure 11: Cross-subsidizing Pooling Contracts

expected repayment to the bank is higher than the repayment that is consistent with their risk levels whereas it is lower for low-type agents. In that sense, effort-providing high-type agents cross-subsidize all other loan applicants due to the fact that the types are not observable by the banks. The loan contract $C^{*}(A)$ is preferred to outside option $\left(R A+p^{e} w\right)$ for every agent, and thus, all agents with these wealth levels apply for loans.

\section{A.2 The first-best efficient separating contracts}

For wealth levels in $[\tilde{A}, I]$, agents are rich enough that separation is possible even with a contract designed for all. The reason is that the rich low-type agents need to borrow less, and thus, do not benefit from the cross-subsidies of the loans. Therefore, their outside option is attractive for them even with a first-best efficient contact offered in the market.

Figure 12 illustrates the equilibrium contract in these wealth levels. As before, $H H^{\prime}$ shows the iso-profit line for high-type agents, $L L^{\prime}$ is that for low-type agents, and $Z P_{H}$ is the zero profit line for banks with high-type agents. In a similar fashion to cross-subsidizing pooling contracts, it can be shown that any contract such as $C_{1}$ cannot be an equilibrium since there always exist a deviation contract (such as $C_{2}$ ) at the north-west of it which is preferred only by effort-providing high-type agents. This time, however, any contract in between $\left[C^{* * *}, C_{3}\right]$ is an equilibrium, since these are not preferred by low-type agents, and they make zero profits with high-type agents who prodide effort. That means there is a continuum of equilibria. The problem now is determining which one is a reasonable one to focus on.

It turns out that, for my purposes, it does not make any difference on which equilibria I focus, since in all of them there is no change in who becomes an entrepreneur or in the expected payment of the loan applicants. The only difference between different equilibria is the payment scheme in both states of the world. Nonetheless, even a small degree of risk aversion would imply $C^{* * *}$ as the unique equilibrium. Thus, I can restrict my attention to $C^{* * *}$ as an equilibrium contract for wealth levels between $[\tilde{A}, I]$. In that case, the equilibrium contract takes the following form.

$$
C^{* * *}(A) \equiv\left[\begin{array}{l}
C_{H}^{* * *} \\
C_{L}^{* * *}
\end{array}\right]=\left[\begin{array}{ll}
D_{H}^{S}(A) & D_{H}^{F}(A) \\
D_{L}^{S}(A) & D_{L}^{F}(A)
\end{array}\right]=\left[\begin{array}{cc}
\frac{R(I-A)}{p_{H}} & 0 \\
\frac{R(I-A)}{p_{H}} & 0
\end{array}\right] .
$$




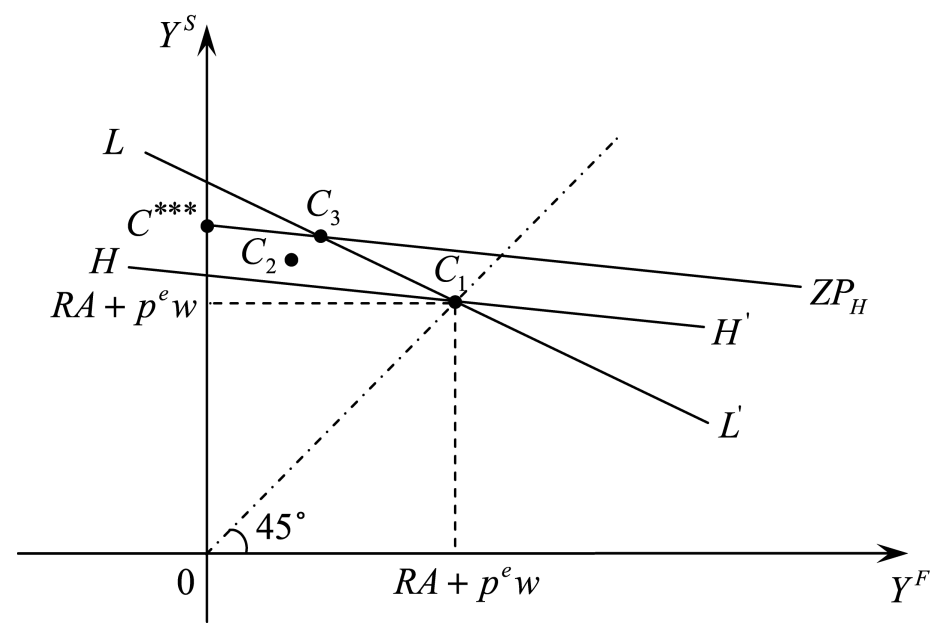

Figure 12: The First-best Efficient Separating Contracts

Note that $C^{* * *}(A)$ is efficient because it can separate effort-providing high-type agents from low-type agents. Moreover, the price of the loan is such that there are no cross-subsidies.

\section{A.3 No-effort pooling contracts}

The discussion of the equilibrium contracts so far neglects the point that there can be wealth levels in which high-type agents do not provide effort in entrepreneurship. They are no different from low-type agents when they do not provide effort. For such wealth levels there is no adverse selection problem since banks can infer the success probability of any applicant, which is $p_{L}$ for all agents, with certainty. I discuss the effort decision in detail when I analyze the decisions of agents. However, it bears mentioning that, in such situations, banks would offer the pooling contract that is consistent with the risk level of the pool:

$$
\boldsymbol{C}^{* * * *}(A) \equiv\left[\begin{array}{l}
C_{H}^{* * * *} \\
C_{L}^{* * * *}
\end{array}\right]=\left[\begin{array}{ll}
D_{H}^{S}(A) & D_{H}^{F}(A) \\
D_{L}^{S}(A) & D_{L}^{F}(A)
\end{array}\right]=\left[\begin{array}{cc}
\frac{R(I-A)}{p_{L}} & 0 \\
\frac{R(I-A)}{p_{L}} & 0
\end{array}\right],
$$

and would make zero profits.

\section{B Appendix: Proofs}

\section{B.1 Proof of Lemma 3}

The equilibrium I focus on in this paper must satisfy $0<A_{e}<A_{L}<\tilde{A}<I$, Assumption 4 , and $A_{H}<A_{e}$. It can be shown that $A_{L}<\tilde{A}$ holds by definition, $0<A_{L}<\tilde{A}<I$ is implied by Assumption 3, and $A_{e}<A_{L}$ implies $A_{H}<A_{e}$. Then, it is sufficient to say that, in any equilibrium I focus on, Assumption 3 , Assumption 4 , and $0<A_{e}<A_{L}$ must be satisfied.

Assumption 3 requires

$$
\begin{aligned}
p_{H} \pi\left(w^{*}\right)-e & >p^{e} w^{*}+R I, \\
p_{L} \pi\left(w^{*}\right) & <p^{e} w^{*}+R I, \\
p_{L} \pi\left(w^{*}\right) & >p^{e} w^{*}+\left(p_{L} / \bar{p}\right) R I .
\end{aligned}
$$




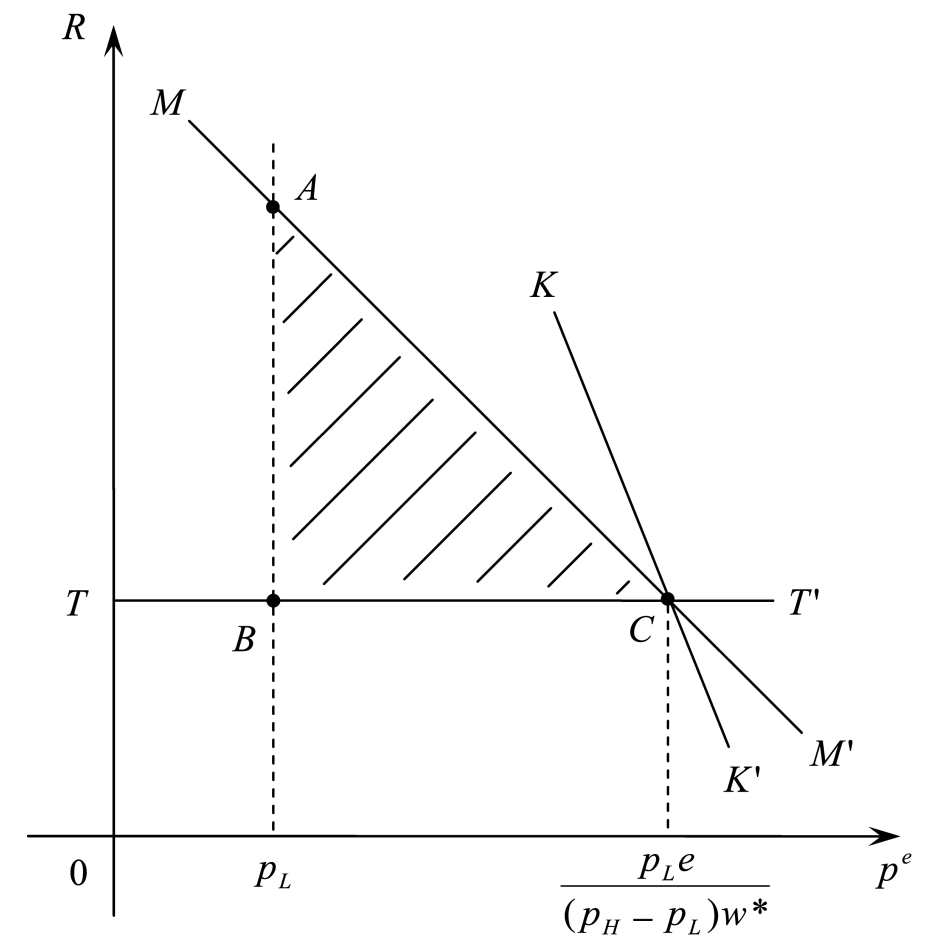

Figure 13: Possible Equilibria in the General Equilibrium

$0<A_{e}<A_{L}$ implies

$$
\begin{aligned}
\bar{p} \pi\left(w^{*}\right)-\frac{\bar{p}-p_{L}}{p_{H}-p_{L}} e & >p^{e} w^{*}+R I, \\
\frac{\bar{p}\left(\pi\left(w^{*}\right)-\frac{e}{p_{H}-p_{L}}\right)}{I} & <R .
\end{aligned}
$$

Assumption 4 indicates that $e>\left(p_{H}-p_{L}\right) w^{*}$. When (B.1c), (B.2a), and (B.2b) are satisfied, (B.1a) and (B.1b) are satisfied as well. Given $w^{*}$, Figure 13 shows where the possible equilibria must lie in general equilibrium. (B.1c) says that equilibrium must lie under $K K^{\prime}$, and (B.2a) says it must lie under $M M^{\prime}$, whereas (B.2b) indicates that the risk-free interest rate has to be above $T T^{\prime}$. Then, any equilibria satisfying Assumption 3, Assumption 4 , and $0<A_{e}<A_{L}$ must be in $(\stackrel{\triangle}{B} C)$. Note that Assumption 4 is needed to guarantee that $p_{L}<\left(p_{L} e\right) /\left[\left(p_{H}-p_{L}\right) w^{*}\right]$ in Figure 13 .

\section{B.2 Proof of Proposition 6}

Note that $p^{e} \in\left[p_{L}, p_{H}\right]$. I prove the uniqueness of equilibrium in two steps. First, I show that the hightype locus is always downward sloping in $p^{e}$ in $(A B C)$. Second, I show that, for some wealth distributions,

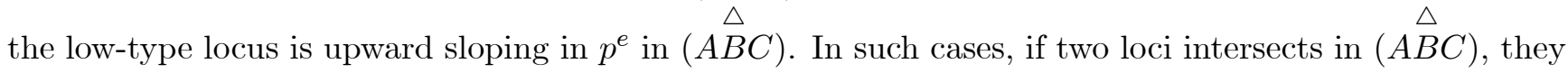
have to intersect only once, and thus the equilibrium must be unique.

Step 1: High-type locus is downward sloping in $p^{e}$ in $(A \stackrel{\triangle}{B} C)$. 
By Implicit Function Theorem

$$
\begin{gathered}
\left.\frac{\partial R}{\partial p^{e}}\right|_{\phi_{H}\left(R, p^{e}\right)=0}=-\frac{\frac{\partial \phi_{H}\left(R, p^{e}\right)}{\partial p^{e}}}{\frac{\partial \phi_{H}\left(R, p^{e}\right)}{\partial R}} \\
\frac{\partial \phi_{H}\left(R, p^{e}\right)}{\partial p^{e}}=-\left(\frac{1}{p_{H}-p_{L}}\right) \frac{\bar{A}}{I}<0 \\
\frac{\partial \phi_{H}\left(R, p^{e}\right)}{\partial R}=\frac{\partial E_{H}\left(R, w^{*}\right)}{\partial R}=h \frac{\partial\left[1-G\left(A_{e}\left(R, w^{*}\right)\right)\right]}{\partial R} .
\end{gathered}
$$

By Leibniz's Rule

$$
h \frac{\partial\left[1-G\left(A_{e}\left(R, w^{*}\right)\right)\right]}{\partial R}=-h g\left(A_{e}\right) \frac{\partial A_{e}}{\partial R}
$$

By Assumption 3

$$
\frac{\partial A_{e}}{\partial R}=\frac{\pi\left(w^{*}\right)-\frac{e}{p_{H}-p_{L}}}{\frac{R^{2}}{\bar{p}}}>0
$$

Hence,

$$
\left.\frac{\partial R}{\partial p^{e}}\right|_{\phi_{H}\left(R, p^{e}\right)=0}<0
$$

Moreover, the right-hand side of (39a) is a function of $p^{e}$ only, and it is zero when $p^{e}=p_{L}$. The left-hand side equals zero only when $A_{e}\left(R, w^{*}\right)=I$, which can happen only when $R=\infty$. Then, the high-type locus has to be convex in $p^{e}$ between $\left(p_{L}, p_{H}\right)$.

The number of entrepreneurs can at most be $\bar{A} / I$. Then, theoretically, the left-hand side of (39a) can at most be $\bar{A} / I$. This happens when all the entrepreneur positions are filled with all high-type agents with a positive interest rate. As far as the high-type locus is concerned, any further decrease in $R$ would not increase the average success probability since all the positions have been filled by high-type entrepreneurs. Then, $p^{e}$ is fixed and equal to $p_{H}$ for any interest rate smaller than this (positive) interest rate. The high-type locus is shown in Figure 8.

Step 2: For some wealth distributions, the low-type locus is upward sloping in $p^{e}$ in $(A B C)$.

By Implicit Function Theorem

$$
\begin{gathered}
\left.\frac{\partial R}{\partial p^{e}}\right|_{\phi_{L}\left(R, p^{e}\right)=0}=-\frac{\frac{\partial \phi_{L}\left(R, p^{e}\right)}{\partial p^{e}}}{\frac{\partial \phi_{L}\left(R, p^{e}\right)}{\partial R}} \\
\frac{\partial \phi_{L}\left(R, p^{e}\right)}{\partial p^{e}}=\frac{\partial E_{L}\left(R, w^{*}, p^{e}\right)}{\partial p^{e}}+\underbrace{\left(\frac{1}{p_{H}-p_{L}}\right) \frac{\bar{A}}{I}}_{(+)} \\
\frac{\partial E_{L}\left(R, w^{*}, p^{e}\right)}{\partial p^{e}}=(1-h) \frac{\partial\left[G\left(A_{L}\left(R, w^{*}, p^{e}\right)\right)-G\left(A_{e}\left(R, w^{*}\right)\right)\right]}{\partial p^{e}} .
\end{gathered}
$$

By Leibniz's Rule

$$
\frac{\partial E_{L}\left(R, w^{*}, p^{e}\right)}{\partial p^{e}}=(1-h) g\left(A_{L}\right) \frac{\partial A_{L}}{\partial p^{e}}=-(1-h) g\left(A_{L}\right) \frac{\bar{p} w^{*}}{R\left(\bar{p}-p_{L}\right)}<0
$$


Then,

$$
\frac{\partial \phi_{L}\left(R, p^{e}\right)}{\partial p^{e}}=\frac{\bar{A}}{\left(p_{H}-p_{L}\right) I}-\frac{\bar{p}(1-h) w^{*}}{R\left(\bar{p}-p_{L}\right)} g\left(A_{L}\right)=\frac{1}{\left(p_{H}-p_{L}\right) I} \int_{0}^{I} A d G(A)-\frac{\bar{p}(1-h) w^{*}}{R\left(\bar{p}-p_{L}\right)} g\left(A_{L}\right)
$$

It is evident that for some wealth distributions $\partial \phi_{L}\left(R, p^{e}\right) / \partial p^{e}>0 .{ }^{29}$ Now turn to $\partial \phi_{L}\left(R, p^{e}\right) / \partial R$.

$$
\begin{gathered}
\frac{\partial \phi_{L}\left(R, p^{e}\right)}{\partial R}=\frac{\partial E_{L}\left(R, w^{*}, p^{e}\right)}{\partial R} \\
\frac{\partial E_{L}\left(R, w^{*}, p^{e}\right)}{\partial R}=(1-h) \frac{\partial\left[G\left(A_{L}\left(R, w^{*}, p^{e}\right)\right)-G\left(A_{e}\left(R, w^{*}\right)\right)\right]}{\partial R} .
\end{gathered}
$$

By Leibniz's Rule,

$$
\frac{\partial E_{L}\left(R, w^{*}, p^{e}\right)}{\partial R}=(1-h)[g\left(A_{L}\right) \underbrace{\frac{\partial A_{L}}{\partial R}}_{(-)}-g\left(A_{e}\right) \underbrace{\frac{\partial A_{e}}{\partial R}}_{(+)}],
$$

and $\partial A_{L} / \partial R<0$ and $\partial A_{e} / \partial R>0$. Then, whenever (B.3) is positive

$$
\frac{\partial E_{L}\left(R, w^{*}, p^{e}\right)}{\partial R}<0
$$

Hence,

$$
\left.\frac{\partial R}{\partial p^{e}}\right|_{\phi_{L}\left(R, p^{e}\right)=0}<0
$$

The low-type locus is shown in Figure 8. In the case in which the low-type locus is upward sloping, the two loci have to intersect once and only once.

\section{B.3 Proof of Proposition 7}

Focus on the economies that satisfy the conditions of Proposition 6. It is sufficient to show that

$$
\left.\frac{\partial R}{\partial t}\right|_{\phi_{H}\left(R, p^{e}, t\right)=0}<0 \text { and }\left.\frac{\partial R}{\partial t}\right|_{\phi_{L}\left(R, p^{e}, t\right)=0}<0 .
$$

In particular, note that I do not need to take into account a change in the wage rate. It is the same before and after the policy since neither the labor supply nor the labor demand has changed.

Step 1: Show that $\left.\frac{\partial R}{\partial t}\right|_{\phi_{H}\left(R, p^{e}, t\right)=0}<0$.

$$
\left.\frac{\partial R}{\partial t}\right|_{\phi_{H}\left(R, p^{e}, t\right)=0}=-\underbrace{\frac{\frac{\partial \phi_{H}\left(R, p^{e}, t\right)}{\partial t}}{\frac{\partial \phi_{H}\left(R, p^{e}, t\right)}{\partial R}}}_{(-)} .
$$

\footnotetext{
${ }^{29}$ For some other wealth distributions $\partial \phi_{L}\left(R, p^{e}\right) / \partial p^{e}<0$, and the low-type locus is upward sloping but a tax on entrepreneurs can still be obtained. For example, focus on a case in which there is a unique equilibrium with an upward sloping low-type locus. Suppose the low-type locus cuts the high-type locus from above. Then, in a similar fashion to Proposition 8, if the policy shifts down the low-type locus more than it shifts down the high-type locus, taxing entrepreneurs is welfare improving.
} 
I have already shown that $\partial \phi_{H}\left(R, p^{e}, t\right) / \partial R<0$ for a small $t$. Now focus on the numerator.

$$
\frac{\partial \phi_{H}\left(R, p^{e}\right)}{\partial t}=h \frac{\partial\left[1-G\left(A_{e}\left(R, w^{*}, t\right)\right)\right]}{\partial t}=-h g\left(A_{e}\right) \frac{\partial A_{e}}{\partial t} \quad,
$$

and

$$
\frac{\partial A_{e}}{\partial t}=\frac{\bar{p}}{R}>0
$$

Thus,

$$
\frac{\partial \phi_{H}\left(R, p^{e}\right)}{\partial t}<0 \text { and }\left.\frac{\partial R}{\partial t}\right|_{\phi_{H}\left(R, p^{e}, t\right)=0}<0
$$

Therefore, a tax-subsidy policy shifts the high-type locus down.

Step 2: Show that $\left.\frac{\partial R}{\partial t}\right|_{\phi_{L}\left(R, p^{e}, t\right)=0}<0$.

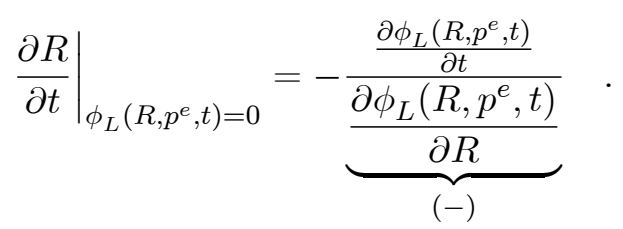

Similarly, I have already shown that $\partial \phi_{L}\left(R, p^{e}, t\right) / \partial R<0$ for a small $t$. Now focus on the numerator.

$$
\begin{aligned}
\frac{\partial \phi_{L}\left(R, p^{e}, t\right)}{\partial t} & =(1-h) \frac{\partial\left[G\left(A_{L}\left(R, w^{*}, p^{e}, t\right)\right)-G\left(A_{e}\left(R, w^{*}, t\right)\right)\right]}{\partial t} \\
& =(1-h)(g\left(A_{L}\right) \underbrace{\frac{\partial A_{L}}{\partial t}}_{(-)}-g\left(A_{e}\right) \underbrace{\frac{\partial A_{e}}{\partial t}}_{(+)})<0,
\end{aligned}
$$

Then,

$$
\left.\frac{\partial R}{\partial t}\right|_{\phi_{L}\left(R, p^{e}, t\right)=0}<0
$$

Therefore, a tax-subsidy policy shifts the low-type locus down.

\section{B.4 Proof of Proposition 8}

Focus on the wealth distributions that satisfy Proposition 6. Let the high-type locus be $R_{H}\left(p^{e}, t\right)$ and the low-type locus be $R_{L}\left(p^{e}, t\right)$. In equilibrium

$$
R_{H}\left(p^{e *}, t\right)-R_{L}\left(p^{e *}, t\right)=0
$$

Total differentiation of (B.4) around the equilibrium yields

$$
\frac{\partial p^{e}}{\partial t}=-\frac{\frac{\partial R_{H}}{\partial t}-\frac{\partial R_{L}}{\partial t}}{\frac{\partial R_{H}}{\partial p^{e}}-\frac{\partial R_{L}}{\partial p^{e}}}
$$

On the other hand, $\partial R_{H} / \partial p^{e}<0$ and $\partial R_{L} / \partial p^{e}>0$. Hence, the denominator is negative. Then, it is sufficient to show that

$$
\frac{\partial R_{H}}{\partial t}-\frac{\partial R_{L}}{\partial t}>0
$$


Since both terms in (B.5) are negative it boils down to

$$
\left|\frac{\partial R_{H}}{\partial t}\right|<\left|\frac{\partial R_{L}}{\partial t}\right|
$$

In words, if the public policy is going to increase $p^{e}$, it must shift down the low-type locus more than it shifts down the high-type locus. The expressions for these have already been derived in (B.6):

$$
\left|\frac{\partial R_{H}}{\partial t}\right|=\frac{h g\left(A_{e}\right) \frac{\partial A_{e}}{\partial t}}{h g\left(A_{e}\right) \frac{\partial A_{e}}{\partial R}}=\frac{\frac{\partial A_{e}}{\partial t}}{\frac{\partial A_{e}}{\partial R}}
$$

and

$$
\left|\frac{\partial R_{L}}{\partial t}\right|=\frac{(1-h)\left(g\left(A_{L}\right) \frac{\partial A_{L}}{\partial t}-g\left(A_{e}\right) \frac{\partial A_{e}}{\partial t}\right)}{(1-h)\left(g\left(A_{L}\right) \frac{\partial A_{L}}{\partial R}-g\left(A_{e}\right) \frac{\partial A_{e}}{\partial R}\right)}=\frac{g\left(A_{L}\right) \frac{\partial A_{L}}{\partial t}-g\left(A_{e}\right) \frac{\partial A_{e}}{\partial t}}{g\left(A_{L}\right) \frac{\partial A_{L}}{\partial R}-g\left(A_{e}\right) \frac{\partial A_{e}}{\partial R}} .
$$

Then, after some manipulation, the problem is whether the following inequality is satisfied or not:

$$
\frac{\frac{\partial A_{e}}{\partial t}}{\frac{\partial A_{e}}{\partial R}} \stackrel{?}{<} \frac{g\left(A_{L}\right) \frac{\partial A_{L}}{\partial t}-g\left(A_{e}\right) \frac{\partial A_{e}}{\partial t}}{g\left(A_{L}\right) \frac{\partial A_{L}}{\partial R}-g\left(A_{e}\right) \frac{\partial A_{e}}{\partial R}}
$$

This boils down to

$$
\underbrace{\frac{\partial A_{e}}{\partial t} \frac{\partial A_{L}}{\partial R}}_{(+)} \stackrel{?}{<} \underbrace{\frac{\partial A_{L}}{\partial t} \frac{\partial A_{e}}{\partial R}}_{(-)}
$$

where

$$
\begin{aligned}
\frac{\partial A_{L}}{\partial t} & =-\frac{p_{L}+\frac{\bar{A}}{I-\bar{A}} p^{e}}{R\left(1-\frac{p_{L}}{\bar{p}}\right)}<0 \\
\frac{\partial A_{L}}{\partial R} & =-\frac{p_{L}\left(\pi\left(w^{*}\right)-t\right)-p^{e}\left(w^{*}+\frac{\bar{A}}{I-A} t\right)}{R^{2}\left(1-\frac{p_{L}}{\bar{p}}\right)}<0 \\
\frac{\partial A_{e}}{\partial t} & =\frac{\bar{p}}{R}>0 \\
\frac{\partial A_{e}}{\partial R} & =\frac{\pi\left(w^{*}\right)-t-\frac{e}{p_{H}-p_{L}}}{\frac{R^{2}}{\bar{p}}}>0 .
\end{aligned}
$$

Substituting these values into the inequality (B.7)

$$
\begin{aligned}
& \frac{\bar{p}}{R} \frac{p_{L}\left(\pi\left(w^{*}\right)-t\right)-p^{e}\left(w^{*}+\frac{\bar{A}}{I-\bar{A}} t\right)}{R^{2}\left(1-\frac{p_{L}}{\bar{p}}\right)} \stackrel{?}{>} \frac{\pi\left(w^{*}\right)-t-\frac{e}{p_{H}-p_{L}} \frac{p_{L}+\frac{\bar{A}}{I-\bar{A}} p^{e}}{R\left(1-\frac{p_{L}}{\bar{p}}\right)}}{\frac{R^{2}}{\bar{p}}} \\
& p_{L}\left(\pi\left(w^{*}\right)-t\right)-p^{e}\left(w^{*}+\frac{\bar{A}}{I-\bar{A}} t\right) \stackrel{?}{>}\left(\pi\left(w^{*}\right)-t-\frac{e}{p_{H}-p_{L}}\right)\left(p_{L}+\frac{\bar{A}}{I-\bar{A}} p^{e}\right) .
\end{aligned}
$$

Then, (B.7) holds if

$$
p^{e *}<\tilde{p}:=\frac{\frac{p_{L} e}{p_{H}-p_{L}}}{\frac{\bar{A}}{I-\bar{A}}\left(\pi\left(w^{*}\right)-\frac{e}{p_{H}-p_{L}}\right)+w^{*}} .
$$

Note that $p^{e}<\tilde{p}$ is likely because the downward sloping high-type locus, $R_{H}$, tends to be very steep due to the facts that $\lim _{R \rightarrow \infty} R_{H}=\infty$ and $\lim _{p^{e} \rightarrow p_{H}} R_{H}$ is finite. I still need to check if $p^{e *}<\tilde{p}$ can hold in 
$(\stackrel{\triangle}{B} C)$. In $(\stackrel{\triangle}{A B C})$, at least

$$
p_{L} \leq p^{e *} \leq \frac{p_{L} e}{\left(p_{H}-p_{L}\right) w^{*}}
$$

has to be satisfied. Then, $\tilde{p}<\left(p_{L} e\right) /\left[\left(p_{H}-p_{L}\right) w^{*}\right]$. Moreover, $p_{L}<\tilde{p}$ when

$$
\frac{\bar{A}}{I-\bar{A}} \pi\left(w^{*}\right)+w<\frac{I}{I-\bar{A}} \frac{e}{p_{H}-p_{L}}
$$

or

$$
E^{*} \underbrace{\left[\left(p_{H}-p_{L}\right) \pi(w)^{*}\right]}_{>e \text { by Assumption } 3}+\left(1-E^{*}\right) \underbrace{\left[\left(p_{H}-p_{L}\right) w^{*}\right]}_{<e \text { by Assumption } 4}<e .
$$

This inequality holds if $E^{*} \ll 1-E^{*}$ since the expression in the square brackets in the first term is higher than $e$ by Assumption 3 and the one in the second term is lower than $e$ by Assumption 4. Therefore, this inequality hold if the number of workers in the economy is sufficiently larger than the number of entrepreneurs. This completes the proof that there is a large class of economies in which tax-subsidy policy can increase $p^{e}$ and, moreover, in such economies this policy is welfare improving.

\section{References}

[1] Acs, Z., P. Arenius, M. Hay, and M. Minniti. 2005. Global Entrepreneurship Monitor (GEM) 2004 Executive Report. GEM Consortium.

[2] Arnott, R., and J. Stiglitz. 1988. Randomization with asymmetric information. Rand Journal of Economics 19: 344-362.

[3] Banerjee, A., and A. Newman. 1993. Occupational choice and the process of development. Journal of Political Economy 101: 274-298.

[4] de Meza, D., and D. Webb. 1987. Too much investment: a problem of asymmetric information. Quarterly Journal of Economics 102: 281-292.

[5] de Meza, D., and D. Webb. 2000. Does credit rationing imply insufficient lending? Journal of Public Economics 78: 215-234.

[6] Feldstein, M., and C. Horioka. 1980. Domestic saving and international capital flows. Economic Journal 90: 314-329.

[7] Gale, W. 1991. Economic effects of federal credit programs. American Economic Review 81: 133-152.

[8] Ghatak, M., M. Morelli, and T. Sjostrom. 2001. Occupational choice and dynamic incentives. Review of Economic Studies 68: 781-810.

[9] Ghatak, M., M. Morelli, and T. Sjostrom. forthcoming. Entrepreneurial talent, occupational choice, and trickle up policies. Journal of Economic Theory.

[10] Gollin, D. forthcoming. Nobody's business but my own: self employment and small enterprise in economic development. Journal of Monetary Economics.

[11] Gruner, H. 2003. Redistribution as a selection device. Journal of Economic Theory 108: 194-216.

[12] Hellwig, M. 1987. Some recent developments in the theory of competition in markets with adverse selection. European Economic Review 31: 319-325. 
[13] Inci, E. 2006. Occupational choice and the quality of entrepreneurs. CEBR Discussion Paper No. 2006-18.

[14] Innes, R. 1993. Financial contracting under risk neutrality, limited liability, and ex ante asymmetric information. Economica 60: 27-40.

[15] Lazear, E. 2005. Entrepreneurship. Journal of Labor Economics 23: 649-680.

[16] Legros, P., A. Newman, and E. Proto. 2006. Smithian growth through creative organization. CEPR Discussion Paper 5709.

[17] Lloyd-Ellis, H., and D. Bernhardt. 2000. Enterprise, inequality and economic development. Review of Economic Studies 67: 147-68.

[18] Newman, A. 2006. Risk-bearing and entrepreneurship. CEPR Discussion Papers 6021.

[19] Mookherjee, D., and D. Ray. 2003. Persistent inequality. Review of Economic Studies 70: 369-394.

[20] Obstfeld, M., and K. Rogoff. 2000. The six major puzzles in international macroeconomics: is there a common cause. In NBER Macroeconomics Annual 2000 edited by B. Bernanke and K. Rogoff. Cambridge: MIT Press.

[21] Parker, S. 2003. Asymmetric information, occupational choice and government policy. Economic Journal 113: 861-882.

[22] Raynold, P. 1995. Federal lending and aggregate economic activity. Applied Economics 27: 947-952.

[23] Reynolds, P., and S. White. 1997. The Entrepreneurial Process: Economic Growth, Men, Women and Minorities. Westport, CT: Quorum Books.

[24] Rothschild, M., and J. Stiglitz. 1976. Equilibrium in competitive insurance markets: an essay in the economics of imperfect information. Quarterly Journal of Economics 90: 630-649.

[25] Stiglitz, J., and A. Weiss. 1981. Credit rationing in markets with imperfect information. American Economic Review 71: 393-410.

[26] Wilson, C. 1977. A model of insurance markets with incomplete information. Journal of Economic Theory 16: 167-207. 